\title{
COMPARATIVE STUDY OF DISTRIBUTION NETWORKS RECONFIGURATION PROBLEM APPROACHES
}

\author{
Ana Moura ${ }^{1, *}$, Juliana Salvadorinho ${ }^{2}$, Bárbara Soares ${ }^{2}$ and Joana Cordeiro ${ }^{2}$
}

\begin{abstract}
This work presents a comparative study between different resolutions approaches applied to the problem of power distribution. The main objective is to present a comparison between the various methods of resolution presented in the literature and the most used by the various authors. For this study, ninety papers that address the problem of reconfiguration of power distribution networks were analysed. The main objective is to reduce the real energy losses in the system, while several constraints regarding distribution are satisfied. The most recent papers were analysed, taking into account the approaches presented by the various authors, the formulation of the problem - namely its objective functions and constraints - the initialization methods and the stopping methods, as well as the results obtained. As such, an analysis and categorization of the various problems and approaches is presented, with the main focus being on the analysis and minimization of energy losses in 33-bus systems.
\end{abstract}

Mathematics Subject Classification. 90-02.

Received October 9, 2019. Accepted July 6, 2020.

\section{INTRODUCTION}

In a world where electricity is part of our everyday life, it is taken for granted by consumers; in other words, it is always available on demand. However, there are numerous situations in which this does not actually happen due to the need for its interruption in the distribution system. This suspension may occur as the result of the triggering of a protective device thanks to a defect, or also due to work and/or maintenance in the system. In order for this whole process to be carried out with minimal interference, it is essential to restrict the area that is to be powered down; a plan for reconfiguration measures is needed, to ensure that downstream consumers do not suffer from this effect. One can explain the distribution of electric energy process in a simplistic way: as a system of energy composed by a generator, a transmitter and a distribution system, where the latter is the part that connects the electrical and energy service to consumers. The purpose of the energy system is to provide electricity to consumers in a reliable and economical way, but this is the main cause of power losses and service interruptions [32]. These distribution systems normally operate in a radial topology, which is the most suitable for protecting and coordinating connection schemes in an unidirectional power current $[51,61,74]$. In a radial topology, each consumer has a single supply source $[15,74]$. By definition, network reconfiguration is the process

Keywords. Distribution networks reconfiguration, heuristic methods, meta-heuristics, multi-objective approaches.

1 DEGEIT - GOVCOPP, University of Aveiro, Aveiro, Portugal.

2 DEGEIT, University of Aveiro, Aveiro, Portugal.

* Corresponding author: ana.moura@ua.pt 
of changing the network configuration, changing the state of normally open and normally closed switches to achieve the objectives $[15,41,74]$ and to meet the operational constraints defined in advanced [74]. The goal and the main concern of the researchers is the necessary reduction in energy losses and the deviation of the sensing voltages. These are influenced by the combinations of state change operations of the switches, that must fulfill the condition of the network being radial, as well as the proper energization of all loads $[17,53]$. This paper focuses on the reconfiguration of power distribution networks, that can be classified as a nonlinear combinatorial optimization problem NP-Hard [24], due to the nonlinear characteristics of the behaviour of electrical constraints and the high number of elements - switches $[24,26,88]$. Network reconfiguration taking into account the concept of loss reduction was proposed in the 1970s, using the exact Branch and Bound algorithm [41,53]. More recently, many are the authors who safeguard themselves by using artificial intelligence in their methods, capable of overcoming the barriers of the more traditional procedures (such as the high computational time) thus ensuring its applicability in a real context. The most applied algorithms focus on populational metaheuristics [41] that, while not guaranteeing the optimal global solution (unlike exact algorithms), present results that are closer to being optimal, together with attractive computational times [5]. Reconfiguration methods are no longer the sole focus of research, but there are more and more approaches that consider the insertion of electronic devices to achieve near-exclusion of energy losses to achieve maximum power distribution efficiency. Distributed generation (DG) is an approach that employs small-scale technologies for producing electricity near consumers. DG resources have been preferred, and this is mainly due to the benefits they bring; such as reduced energy losses, improved voltage profile and power quality and increased reliability, ensuring greater safety for critical loads $[17,26,37,81,88]$. DGs use Distributed Generation Units (DGUs) that generate electricity from nearby power sources such as solar panels, wind turbines, etc. [17,61,65,79,85,89]. Although there are already several studies on the Distribution Feeder Reconfiguration (DFR) problem without considering the effects of DGs, few already take into account their influence. In addition to the many benefits they bring to the distribution system, they can also compromise its stability, as they affect the characteristics of the reactive power flow in the network $[29,31,89]$. Essentially, DG systems really have the ability to reduce energy losses and balance the load level on the network to a certain level of penetration $[20,31]$. However, when it increases to high values, the DG changes the flow direction and causes friction in the load transfer within the network [20]. This fact reinforces the idea that the allocation and sizing of these units becomes preponderant when they are inserted into the power distribution network $[6,20,33,37]$. However, and due to the increased integration of DGs, studies related to increasing the ability of DGs to host the network through their combination with Soft Open Points (SOP) devices, have been a concern. The latter are electronic devices, considered flexible and installed in Normally Open Points (NOP) locations in the power distribution networks. SOPs are capable of providing an active energy flow and compensate for the reactive energy generated $[8,9,89]$. Reactive energy, although not performing work, is required in magnetizing the equipment coils (motors, fans, pumping systems), but its flow must be controlled as it is strongly associated with voltage drops and losses by heating [60]. Thus, and because of this enormous impact of reactive energy, capacitor groups have long been used to control it. Yet, these devices are not capable of constantly producing variable reactive energy. To solve this problem, the Distributed Flexible AC Transmission System (D-FACTS) emerged, which are devices or "smart wires" that can change the line power flow where they are installed. In this group, there is a powerful device called Distribution Static Compensation (D-STATCOM) [79]. D-STATCOM has also been integrated into the network by researchers. It achieved results such as the improvement of efficiency and reliability of the distribution system, by reducing energy losses and furthering the voltage profile $[20,60,79]$. All the indicated devices provide strong advantages, but they always come with their own disadvantages. Algorithms must be developed and implemented to determine their optimal location and allocation in the network, to then be able to mitigate their irregularities. Several references that focus on the problem of optimization of the reconfiguration of the power distribution networks were analyzed in this work. Given that the papers have different approaches, the main contribution of the analysis presented here is the categorization of the methods, the relevance of the integrated devices and the comparison of results (only for 33-bus networks - Fig. 1), to verify their applicability in a real context. 


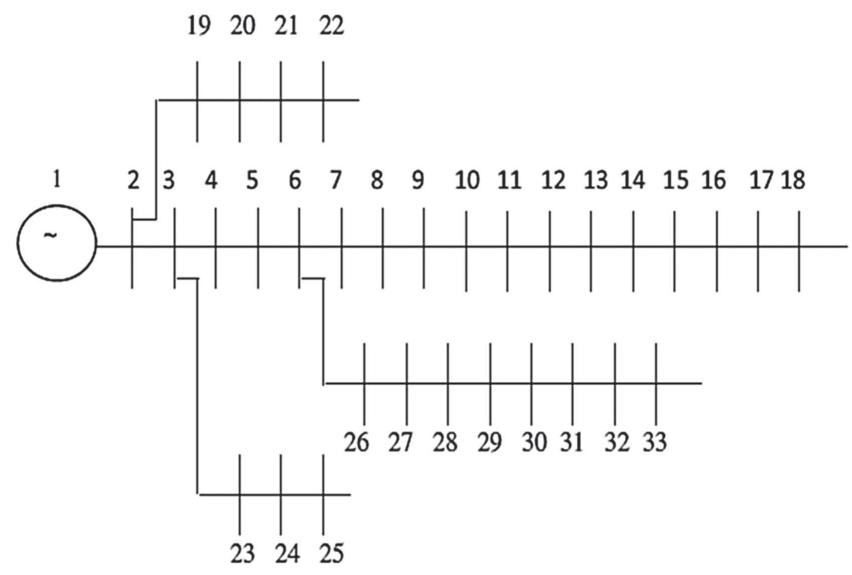

FIgURE 1. Single line diagram of IEEE 33-bus radial distribution network.

\subsection{Problem formulation}

The network reconfiguration problem can be formulated as a combinatorial optimization problem, searching for a feasible solution that must satisfy a group of operational constraints. Usually, researchers tackled the objective function formulation of this problem from two different viewpoints: single objective function and a multi objective function. Nevertheless, the most commonly considered objective function is the power losses.

Considering that:

- $N_{\text {bus }}$ is the total number of buses;

- $N_{\text {br }}$ is the total number of branches;

$-i$ is the bus number;

$-j$ is the branch number;

- $I_{j}$ and $R_{j}$ are the current and resistance at branch $j$, respectively;

- $V_{i}$ is the bus voltage magnitude;

- $P_{i}$ and $Q_{i}$ are the generated bus active and reactive power, respectively;

- $P D_{i}$ and $Q D_{i}$ are the demanded bus active and reactive power, respectively;

- $P_{\text {loss }}$ and $Q_{\text {loss }}$ are the active and reactive power losses in the system, respectively.

The line losses minimization during operation could be formulated as:

$$
\begin{aligned}
\text { Min PL } & =\sum_{i=1}^{N R}\left(I_{j}^{2} \times R_{j}\right) \\
\text { s.t. } \quad & \\
V_{\min } & \leq\left|V_{i}\right| \leq V_{\max }, \forall i \in N_{\text {bus }} \\
\left|I_{j}\right| & \leq I_{\max }, \forall j \in N_{\text {br }} \\
P_{\min } & \leq P_{i} \leq P_{\max }, \forall i \in N_{\text {bus }} \\
Q_{\min } & \leq Q_{i} \leq Q_{\max }, \forall i \in N_{\text {bus }} \\
\sum_{\text {bus }} & P_{i}=\sum_{i=1}^{N_{\text {bus }}}\left(P D_{i}+P_{\text {loss }}\right) \\
\sum_{\text {bus }} & Q_{i}=\sum_{i=1}^{N_{\text {bus }}}\left(Q D_{i}+P_{\text {loss }}\right)
\end{aligned}
$$




$$
\begin{aligned}
N_{\text {main loops }} & =\left(N_{\text {br }}-N_{\text {bus }}\right)+1 \\
N_{\text {br }} & =N_{\text {bus }}-1 .
\end{aligned}
$$

The objective is the power losses (PL) minimization (Eq. (1.1)). All variables in the power system have either physical or engineering limits, which must be considered in the power flow equations, in order to obtain a practical solution that does not violate the operation limits for the system. So, equation (1.2), states that the bus voltage magnitude should be within the permissible limits to maintain power quality. The magnitude of the feeder's branch current $\left(I_{j}\right)$ should not exceed the maximum value of the allowed current passing in the branch $\left(I_{\max }\right)$ (Eq. (1.3)). Equations (1.4) and (1.5), are related to the power generation limits; the active and reactive power, respectively. The other two equations (Eqs. (1.6) and (1.7)), are the power balance equations for the active and reactive power injected into the electrical power system. Equations (1.8) and (1.9) are related to radial typology. The distribution system should be radial without meshes. Normally all loads are served without

disconnections. Each loop should contain a tie line and a corresponding sectionalizing switches. Thus, to retain a radial network structure, when a tie is closed in a loop, only one switch should be open in the same loop. In order to do that, the total number of main loops obtained by closing all the ties and the total number of sectionalizing switches are given by equations (1.8) and (1.9), respectively. The total number of tie switches should be the same as the number of main loops.

In addition to the aforementioned, objectives could be added to the main objective function in order to better characterize and define the problem that is to be solved. The total voltage deviation and the total cost are the second most commonly considered objective functions that sometimes are applied and used individually, and other times, in multi objective approaches, are considered as a secondary objective.

\subsection{Contribution}

The mathematical programming provides accurate solutions for this problem; however, mathematical programming needs considerable computational time to achieve a solution, especially for more complex and large networks. So, other methods and technics are used to solve the distribution networks reconfiguration problem. Section 2 presents various approaches to the problem, using integration of DGs and electronic devices, to enhance the effects of the reconfiguration.

The main idea of this work is to make a bridge between the operational research technics and the distribution energy problems, so, in Section 3, an analysis of the various approaches to problem solving and optimization was made, where a comparison between different heuristic and metaheuristic approaches is presented. In order to study the approaches' efficiency, other fundamental parameter that should be analyzed, between the several approaches, a start stop criteria was used. In Section 6, a comparative analysis of the start and stop criteria defined in the different papers is presented and a bridge is made between these and the consumed computational time.

According to the problem complexity and the big variety of problems presented in the literature, it was necessary to make comparative analyzes of the various objectives and constraints adopted by the various authors (Sects. 4 and 5). In order to summarize all the assumptions, in Section 7, regarding the conclusion, the advantages and disadvantages of the different approaches and a summary of the comparative analysis (Appendix A) are presented.

\section{Distribution networks - Integration of DGs And EleCtronic Devices}

Depending on the relationship between production and consumption in a distribution network, its behavior may vary. If production is less than peak consumption, the local distribution network acts according to its original function, i.e. it is a consumer of the processing network. However, if consumption is below production, the network will act as a power plant connected to the processing network [10].

However, unlike transmission networks, distribution networks have no bilateral flows, operate radially and most substations are not remotely controlled (so it is difficult to have real-time information on energy flows). 
Using smartgrids - remote control of networks - could be a solution to this problem, as it would make it possible to monitor voltage and current conditions in the network and automatically manage the network based on the data collected. However, this reality will not be implemented in all systems in the near future. It is also necessary to evaluate other methodologies for the current challenges of power distribution, because as consumption increases, the networks tend to be expanded; which translates into increased costs and management complexity [10].

There are several ways to improve these systems and thereby reduce energy losses and costs, including the introduction of capacitors, the introduction of DGs, load management, network reconfiguration and the use of other balancing devices [83]. Currently, the introduction of DGs and devices such as SOP and D-STATCOM has been reviewed by several researchers, who prove their efficiency. There is also a tendency to aggregate these methodologies and devices, showing a very promising strategy, which adds new opportunities for research.

\subsection{Distributed generators}

The introduction of Distributed Generators has been promoted in recent decades and considered as a response to the crisis in the energy sector and environmental concerns - with generators integrated in Active Distribution Networks (ADN) [29,31].

Network stability, reliability and security must be ensured by these systems, and placing DGs near loads can increase these indicators. The extensive use of renewable energy facilitates the reduction of congestion, the carbon footprint, the need for network reinforcements and the costs of electricity delivery [28]. However, the relevance of optimizing the size and location of these generators in order to reduce energy losses and operating costs of ADN cannot be overlooked.

From a broad perspective, one must also take the following into account when choosing the location of DGs:

(1) economic and energy factors - areas rich in renewable energy, existence of consumption, networks with capacity;

(2) urban planning - planning in areas with concentrated consumption; plan and stimulate activities where consumption coincides with typical daily production of renewable energy;

(3) technological factors - intelligent systems to align and optimize flows.

There are four different types of DGs mentioned in the literature [65]:

- Type 1 - injects active energy and operates in unit cells, e.g. PV, wind turbines, etc.

- Type 2 - injects reactive energy, which includes compensators and capacitors;

- Type 3 - injects active and reactive energy, such as cogeneration systems and gas turbines;

- Type 4 - consumes reactive energy and injects active energy.

Type 1 and type 3 optimization of DG allocation is tested in a paper presented by Vijay Babu and Singh [83]. On the other hand, in 2018, Reddy et al. [65] test type 1, type 2 and type 3 DGs and the same situation, but without any implementation of DGs. Both studies conclude that type 3 DGs have better performance due to the aforementioned characteristic; in other words, in being able to inject the active and reactive energies into the network.

In [58], the authors conclude that the more widespread the DGs in the network, the greater their penetration level. Usually considered as the minimum load supplied to DGs for their maximum energy output, the penetration of DGs is an important indicator to take into account in the study about optimization of these generators.

Although DGs are a rich source of renewable energy, according to a study by Haoran et al. [30], it should be noted that their natural intermittence and unbalanced ADN conditions cause inefficiency and operational congestion in the system, resulting in a greater flexibility of operations. 


\subsection{Soft open points}

SOPs are electronic power devices installed between the feeders adjacent to the distribution network. They replace the normally open switches in the ADN, capable of controlling active and reactive energy flows through their contact points, facilitating the balance between demand and supply.

Distribution systems have traditionally been unable to cope with the wide penetration of mainly intermittent DGs [84]. This is due to their tuning parameters and the reconfiguration of power networks often entailing a short response time, as well as safety risks due to switch state change operations [30]. SOPs are therefore an effective tool as they have the ability to regulate voltage levels and increase the penetration of DGs [58]; with the potential to promote the economy, flexibility and control of power networks. Therefore, by regulating the operation of SOPs, it is possible to mitigate the imbalance and decrease ADN losses [84]. In addition, they can also be considered as an alternative to network augmentation/reinforcement, which would bear much higher costs [45].

SOPS can actively control energy flows by transferring energy from more congested points to less energized ones. According to Chao Long et al. [45], SOPs have the following advantages over network reconfiguration:

- flow regulation on a continuous basis;

- flexible and accurate control of active and reactive energy;

- short circuits do not increase due to almost instantaneous current control;

- possibility of connection to any group of feeders, from different substations or at different voltage rates.

However, some authors argue that in an ideal scenario these should be allocated at the same time as the network reconfiguration, maximizing the advantages of both approaches. Network reconfiguration allows for the restructuring of the network topology, creating feeder imbalances so that SOPs can control them. In this way, energy can be used and distributed more efficiently [58], while these efficient intelligent devices provide safer, more accurate and real-time control.

These devices typically use back-to-back Voltage Source Converters (VCSs) [45]. It is precisely these converters that give the ability to quickly control active energy and independently exchange reactive energy with transmission systems. There are different types of SOPs: conventional, multi-terminal and with energy storage [31]. Multi-terminal SOPs consist of multiple groups of two-way AC/DC converters whose DC side is connected to the DC node in parallel, and the AC side is connected to the end of each feeder. These are better than the conventional (dual-terminal) ones as they allow greater connection flexibility between multiple feeders, with fewer converters. Thus, the efficiency of equipment use is higher and there is a decrease in investment costs [30].

Studies such as Qi and Wu [58] and Wang et al. [85] show that with reconfiguration and application of SOPs, the penetration level of DGs is higher; however, performance is affected by the location of DGs. SOPs also have (with or without reconfiguration) the ability to limit node voltages and branch currents to allowable values which is not something that only happens with network reconfiguration. In [29], the study indicates that SOPs adjust the energy flow between connected feeders with precision, which responds quickly to varying DGs and loads. The study presented by Chao Long et al. [45] reflects the safety of the use of SOPs - meaning that no system overload occurred with their presence, contrary to what happened in their absence. There is also a high level of penetration, as the VSCs present in SOPs rapidly begin to consume reactive energy - as the current decreases in certain network regions [45].

Despite the many advantages and the fact that these devices are already commercialized, it is essential to develop control strategies. These policies and their impacts have not yet been sufficiently studied to draw effective conclusions on the various conditions of use [45]. In addition, there is always a need for investments; thus also optimizing device allocation [84].

\subsection{D-STATCOM}

There is now a global acceptance of the application of electronic power devices and they are even more suitable than traditional methods [70]. 
Placing DGs at various locations in the network, alters the conventional system structure, creating micro networks - a network with small interconnected systems [28]. As mentioned previously, the use of renewable energy through DGs is important, but it does not correspond to the total response to energy needs and, furthermore, their intermittence undermines network stability, reliability and security [4,28].

D-STATCOM (Static Synchronous Compensator) is a type of FACTS (Flexible AC Transmission Systems) shunt compensator used in power distribution (at low voltages). These devices have the ability to inject and absorb reactive and active energy into the nodes and are a cost-effective solution for compensating network load imbalances and reactive energy control [28]. They act as a capacitor when the system needs reactive power and as an inductor when there is excess of it. They essentially consist of: DC capacitor, AC filter, one or more inverters, a PWM controller and a transformer [60]. The advantages of these devices are [20,60]:

- decreased harmonic distortion;

- decrease of energy losses;

- do not have resonance problems;

- small in size;

- operate automatically;

- operate continuously.

Again, network reconfiguration, despite being subject to optimization processes, is not sufficient to improve voltage profiles. The use of DGs to meet optimal demand levels can be optimized with D-STATCOM allocation.

There are approaches that compare the execution of reconfiguration and later integration of DGs or D-STATCOM. In the work developed by Selvaraj Ganesh and Rajangam Kanimozhi [20] the authors conclude that the best scenario - the one where the loss reduction was much higher - was the one where the reconfiguration and installation of DGs as well as D-STATCOM was done simultaneously. On the other hand, Fahad Iqbal et al. [28] do not contemplate reconfiguration analysis; however, they find that losses are more significant only by allocating DGs, but the use of DGs and D-STATCOM simultaneously results in a much larger reduction. In [49], Pawan Kumar et al. test the system for network reconfiguration and D-STATCOM, concluding that both tools simultaneously increase reactive energy quality, voltage stability, and the capacity/stability of the system supply process.

Several studies of D-STATCOM allocation optimization (size and location) already exist, but there is still a lack of comparison between them [70]. In addition, many of the studies focus on introducing just one DSTATCOM device, but could incorporate more devices, or even multiple combinations between multiple DGs and D-STATCOM. Most research focuses on balanced issues, which highlights the shortcoming of working in unbalanced networks - which is the closest to reality [70].

\subsection{Other methods}

One of the problems that can also be found in distribution networks is phase unbalance. This includes unbalanced loads due to asymmetric loads (such as single-phase and double-phase), unstable load allocation or the emergence of generation technologies with random behaviors $[35,88]$. This issue causes a stalemate in the power system and reduces the network quality by increasing energy losses.

Re-phasing is an alternative method to using capacitors or other load balancing devices. However, since it is a mixed-integer problem, computational time and effort has been hampering the use of this technique which leads to the need to optimize the process through algorithms and metaheuristics [35]. Mohammad R. Kaveh et al. [35] carried out a distribution network optimization study and concluded that although re-phasing decreases energy losses, the re-phasing strategy added to network reconfiguration and DGs integration achieves better results.

\subsection{Network reliability}

The use of alternative energy sources, smartgrids and the introduction of other technologies, is intended to make energy distribution systems increasingly sustainable, as well as to increase confidence and security in 
networks. However, it is necessary to model the various factors that affect network reliability; such as variability in loads and power generation, storage device performance, demand responsiveness, and so on.

One of the aspects that most influences the reliability index in networks is the strategy implemented to restart supplies; essentially, how technologies will be used to minimize the impact of failures. By way of example, if there is a power failure, DGs can guarantee supply in the affected areas, which would not be possible with only primary substations [16]. DGs can be operated in two different ways:

(1) "Island" mode, i.e. DG units located in areas that are isolated from primary substations upon failure;

(2) "Connected Network" mode, where DGs are allocated in areas of the network that have NOP (Normally Open Points) with limited capacity to transfer energy; in this case, DGs can be used to enhance this transfer.

Alberto Escalera et al. [16] report that the use of "island" DGs has been the most proposed technique in the literature, and among the various studies, the most realistic are those that consider chronological fluctuations in power and load generation during failures.

It is therefore essential to take into account numerous factors in assessing distribution systems and choosing techniques to use; this is in order to mitigate the impacts of outages and increase responsiveness in unforeseen and unwanted situations.

\section{Approaches to Problem Resolution AND Optimization}

The optimization problem of power distribution networks, as mentioned earlier, can be framed as a nonlinear, combinatorial, NP-hard problem. The need to optimize such problems increases the challenges regarding the most appropriate tools to use, due to their high computational complexity. In recent years, several authors have used different methods and approaches while comparing them, in an attempt to determine those that can provide the best possible balance between the solution and the desired time to obtain a solution.

A. Rezaee Jordehi [32] considers that there are three main approaches to power distribution network optimization:

- Classic approach, which includes deterministic algorithms, applied to linear programming, nonlinear programming, and dynamic programming. They are generally not efficient in terms of computational times, and there are few applications.

- Approach based on technical criteria: no optimization algorithm is used, one tries to find an optimal result through technical strategies.

- Approach by metaheuristics: widely used in recent decades and have had promising results in solving the problem.

From the range of papers that were analyzed, the authors choose different approaches and these can generally be grouped into the three mentioned above. However, there are also works that use heuristic approaches, hence this approach method is also considered in this paper. The following graph (Fig. 2) shows the percentage of works using each of these approaches. Regarding the approaches using populational metaheuristics, these were further subdivided into three groups: Non-populational, Populational and Hybrid.

The populational metaheuristics were then subdivided into four subgroups (Fig. 3): Swarm Intelligence, Evolutive, Intelligent Algorithms and Immune System. In Figure 3, we present the 4 groups of algorithms most used within the populational metaheuristics. Of the papers with these metaheuristics, about $50 \%$ uses swarm intelligence, $30 \%$ evolutionary, $9 \%$ intelligent algorithms, and $6 \%$ immune system-based algorithms.

\subsection{Deterministic algorithms, linear and nonlinear programming}

In most papers that use nonlinear formulations, the original model is a non-convex nonlinear programming model that is later converted into a SOCP model (Second-Order Cone Programming) through convex relaxation.

In addition to the above formulation and to decrease the deviation from the attached relaxation, Haoran Ji et al. [31] developed a DCP approach (Difference-of-Convex Programming) to solve the problem. According 


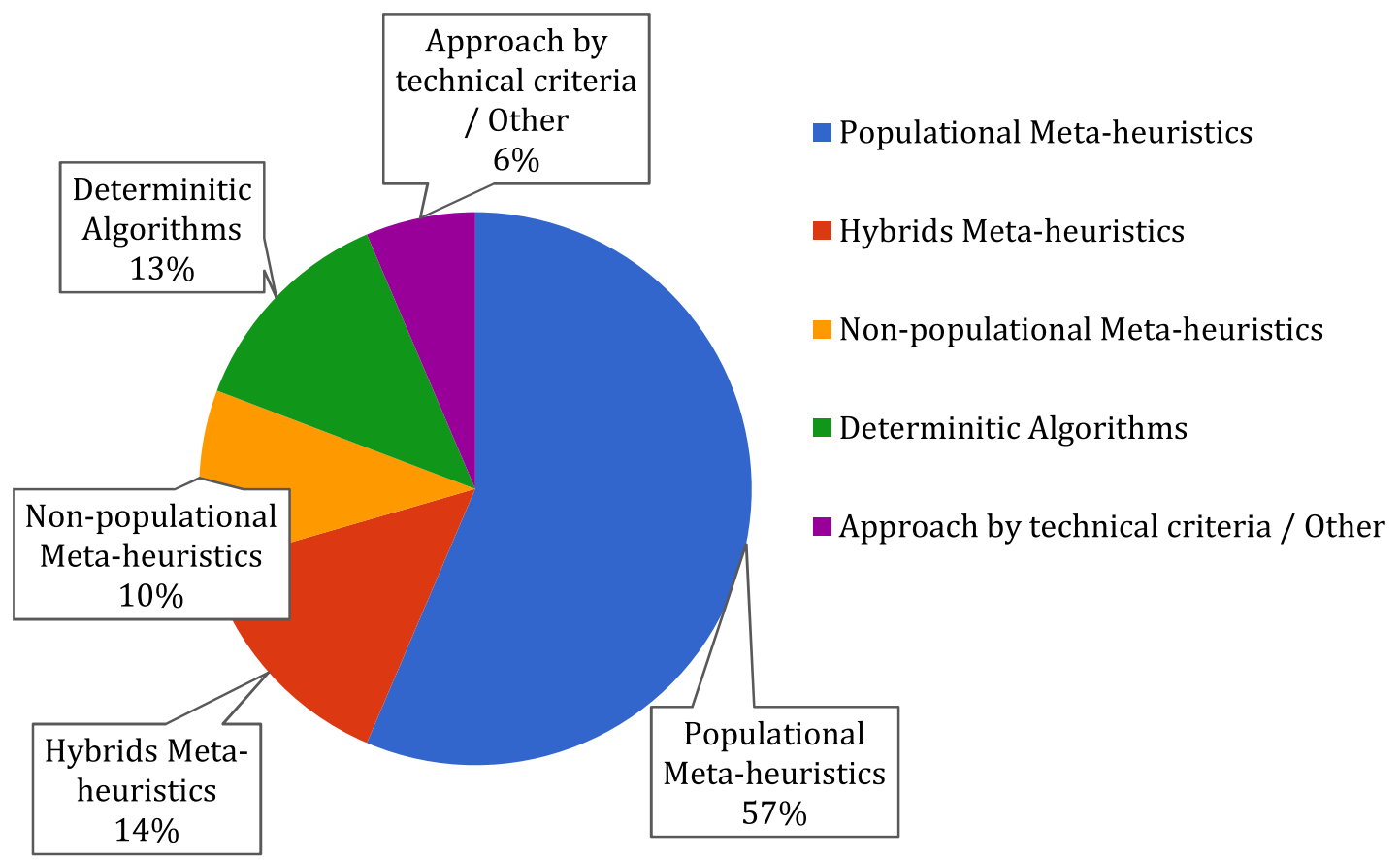

FiguRE 2. Grouping of the approaches used.

\section{Algorithm groups used within Populational Metaheuristics}

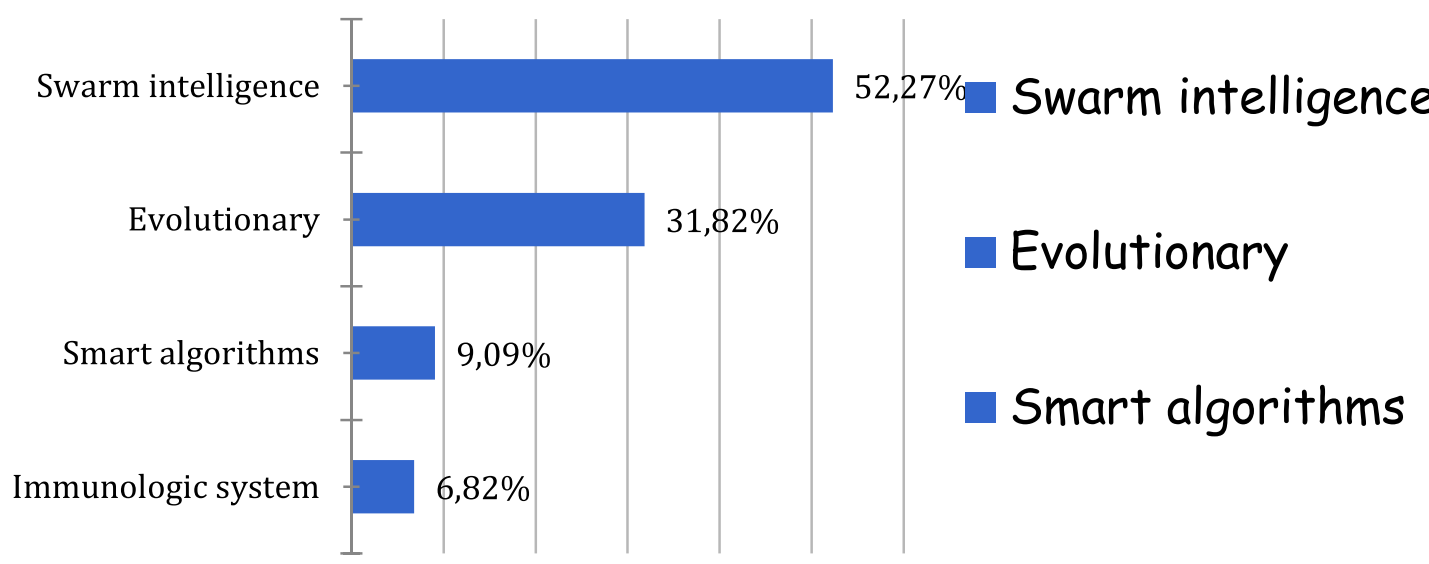

Figure 3. Subdivision of populational metaheuristics. 
to the authors, it ensures a satisfactory result with better computational progress. The main objective is to integrate, soft open points into the network through this method, in order to improve the penetration of DG devices.

In the study presented by Chao Long et al. [45], a basic sensitive method is used in the Jacobian matrix, to define the operational region of the SOP, before using nonlinear optimization to determine the exact operating points of the SOP. GAMS software (General Algebraic System Modeling) is used in both [37,83], as Babu and Singh apply it in [83] to determine the optimal size of DG, using the sensitivity method of energy loss to the location. On the other hand, Kianmehr et al. [37], consider the reconfiguration, together with the optimal location and dimensioning of devices for resolution in the environment of this system.

Yuji Takenobu et al. [76] propose to develop a scalable method and to do so, decomposing the initial problem into sub-problems and always applying the condition of radiality. These sub problems are solved with secondorder conic programming and the results of the combinations are aggregated by a ZDDV vector (Zero-suppressed Binary Decision Diagram vector). The ZDD (Zero-suppressed Binary Decision) is a data structure that brings together all combinations as a direct acyclic graph.

In a linear programming approach, found in [39,88], the authors convert the problem into an MILP (Mixed integer linear programming). Kovacki et al. [39] convert it through a path-switch-to-switch approach, which uses the groups of nodes and branches that are supplied by the same power source to make the MINLP (Mixed integer nonlinear programming) into a MILP (mixed integer linear programming). This MILP is solved through a Lagrange relaxation approach, making the algorithm scalable, which makes it so the computational time does not increase exponentially with the increasing problem size. In turn, Zhai et al. [88] use a dynamic model that takes into account the nature of load variation and generates a switch control sequence. This is done to minimize the costs of power losses over specific and anticipated time periods, rather than reducing losses only as a fixed condition. The model presented in this last work, Zhai et al. [88], also considers the three-phase voltage and power imbalance and uses linearization methods (circular constraints and quadratic loss linearization in the branches). They are introduced to convert the complex problem into a mixed integer linear programming model (MILP), which can be efficiently solved using solvers from various software on the market.

It is necessary to understand that many of the existing solvers for mixed integer linear or nonlinear programming problems rely on the use of branch-and-bound methods, and so, as the network size increases, optimal solution takes much longer to find; thus, authors need to find strategies that allow algorithms to be scaled [76].

\subsection{Approaches by technical criteria and others}

Iqbal et al. [28] use the LSF (Loss Sensitivity Factor) to determine the optimal location of DGs and DSTAT$\mathrm{COM}$, in order to achieve the minimization of energy losses and an improvement in the voltage profile. The LSF reduces the search space, which helps in the calculations required for process optimization. Thus, the nodes with the highest LSF are the ones that best fit the location of DG devices. Voltage deviation is used for the location of DSTATCOM, as when allocating DGs there are nodes that have power outages, and the DSTATCOM device is introduced into the network to solve this problem.

In addition to using sensitivity indexes, Gupta and Kumar [60], use two indexes as a comparison of results to determine the optimal location for DSTATCOM, namely the energy loss index and the voltage stability index. Here the node with the highest value, for either index, is the one selected for allocation. For the determination of the optimal dimension, Gupta and Kumar [60] uses a variational technique.

Maya and Jasmin [48] present a method based on the current summation method, using the forward-backward sweep algorithm to which a modified iterative scale technique for energy flow analysis is added. This method is used to include DG devices in the network and is capable of handling these units as PQ (load nodes), where both active and reactive energy injection are known, or PV (photovoltaic nodes), where the active energy injection and voltage magnitude are known.

In a completely different approach from the previous ones, Cao et al. [9] use Powell's direct tuning method which aims to determine the optimal operating condition of SOP (Soft Open Points) in addition to network 
reconfiguration. This technique can determine the local minimums of a function; however, it needs to be nondifferentiable. To improve the whole process, Cao et al. [9] adds a genetic algorithm to perform selection, crossover and mutation operations, in order to diversify the population.

In the paper presented by Chicco and Mazza [11] uses the OPSID (Optimization Performance Indicator Based on First-Order Stochastic Dominance), an indicator that considers probabilistic distributions of the solutions found by various algorithms and allows the perception of which comes closest to the global optimal, regarding the reconfiguration of power distribution networks. This method can be applied to compare:

- solutions of different heuristics;

- computational effort of different solvers that provide the same solution to a problem;

- heuristic iterations for different parameters;

- computational method results applied to non-convex problems with optimal locations, when the solution depends on the initial one.

\subsection{Heuristics}

Ghasemi and Moshtagh [22] apply a heuristic based on the Branch-Exchange algorithm; in other words, where the reduction of energy losses is achieved through changes in the selection of switch pairs. However, as the algorithm has been widely applied in network reconfiguration, some limitations are noted - such as the dependence of the initial state of the network, the non-guarantee of the optimal solution and the time-consuming process required to select the switch pairs to be considered. Taking these factors into account, Ghasemi and Moshtagh [22] presents a modified heuristic, focusing on changes in the coding of the problem, using tree graphs. These changes prevent unpowered points in the network and closed loop formation. The original BranchExchange algorithm starts with a permissible radial structure and creates new solutions, applying changes to each iteration, and choosing the one that has the best value for the objective function, without compromising the constraints. The method presented by Ghasemi and Moshtagh [22] significantly reduces the computation time, as it evaluates the node-power parameter - which does not need the energy flow calculation - instead of evaluating the node-voltage, which does require the calculation. In addition, it adds a set of heuristic rules to ensure allowable solutions that respect the coding matrix. Thus, the results have high convergence for the optimal solution in a large scale context.

The authors Li et al. [43] apply the exact algorithm MST Method (Minimum Spanning Tree). This exact algorithm is based on graph theory, commonly used to specify specific relationships between objects. It can be described with a set of points, also called vertices, that represent objects, and by sets of lines, or edges, that represent the relationship between objects. The method proposed by $\mathrm{Li}$ et al. [43] is a strategic technique that does not depend on the initial network topology, but does not guarantee the optimal solution. The authors proceed with the reconfiguration in three phases: firstly, implementing MST to search for a local optimal, then applying heuristic rules that present alternative solutions (best solutions), and finally make a correction to the solution that was found. The purpose of applying heuristic rules is to significantly reduce the number of evaluated switches and, therefore, a greater computational efficiency is achieved. Rosseti et al., in works published in 2013 [67] and 2014 [33], use constructive step-by-step heuristics. The first uses a Combined Heuristic Constructive Algorithm (CHCA) that is based on sensitivity indexes and considers the radial configuration of the network and the connectivity of constraints as mandatory conditions. In addition, the proposed method uses a new branch which is built for connecting the DG to the system. This innovative strategy allows for the consideration of the impacts of branch connection parameters, such as impedance. However, in [13] they use a Dynamic Switches Set approach that is adapted to changes in power networks and that avoids the rapid convergence of the algorithm. It ensures that radial topologies are obtained from the outset, so it is not necessary to confirm this condition. It also takes changing demand into account and determines the sequence of switch state operations to obtain allowable operating points throughout the various process steps. Bayat et al. [5,6] implement a constructive heuristic method called Uniform Voltage Distribution Based Constructive Algorithm (UVDA), based on the equal distribution of the voltage of the end nodes. In both, initialization is performed by considering a subnet 
consisting of root nodes (these are substations at the beginning of feeders), primary main nodes (nodes connected directly to root nodes) and candidate nodes (nodes connected directly to primary main nodes). Both guarantee the radial configuration of the network by creating twin nodes, that is, when two branches meet on a single node, two similar nodes are created. It is, therefore, at this stage that the switches which should be left open are determined. When twin nodes appear, the switch that is just above the least-tensioned twin node opens. When these are not met, the node with the highest tension is added to the candidate node group and Branch-Exchange operations are performed. All candidate nodes should be reviewed, which is the stop criterion of the methods. In [6], the authors report that compared to heuristic methods, metaheuristics present a higher computational weight for mono-objective problems. The methodology presented in [6] is a continuation of the work done in [5] by Akbar Bayat in 2013. In [5], the author presents the UVDA algorithm as a solution for power network reconfiguration problems. However, in [6], they add DG mechanisms to their approach, addressing both their allocation and sizing, whereas reconfiguration by itself does not lead to optimal configurations (all end nodes must have the same magnitude of voltage); yet, with the allocation of DGs, it is possible to reach an optimal configuration from a non-optimal one. In fact, it is observed that by simultaneously implementing a network reconfiguration and the installation of DGs, the energy losses decrease significantly.

In [21], Sasan Ghasemi implements a modified heuristic that focuses on reconfiguring the network and minimizing two objectives, the cost of energy losses and the cost of disruption to consumers. In addition to considering unbalanced networks, the authors added mutation processes to the heuristic, which aim to avoid optimal locations and explore new areas of research space.

\subsection{Metaheuristics}

Metaheuristics are essential tools for solving difficult problems in many areas. These allow for the creation of an interaction between local improvement procedures and high-level strategies to create a process that escapes optimal locations, by performing a robust search in the solution space [77]. Moreover, they have proven to be quite effective over time and have now become the most requested when dealing with problems of a complex nature, particularly of combinatorial origin [77].

Metaheuristics can be classified as follows:

(1) Non-populational or single-solution based metaheuristics: focuses on improving only one solution per iteration; in other words, it iteratively generates neighborhoods starting from a single solution, with a shift to another solution from the solution space [77].

(2) Populational or populational-based metaheuristics: unlike the previous one, this type of algorithm aims to improve a population of solutions in each iteration. This method starts by creating an initial population, then generates a new "subpopulation", and is integrated into the original population later, using certain selection procedures [77].

(3) Hybrid metaheuristics: the combination of metaheuristics has proven to be an interesting approach, achieving results for real problems or classic problems that surpass other more classic approaches. There are four different types of combinations: combining metaheuristics with complementary metaheuristics; combining metaheuristics with exact methods from mathematical programming approaches; combining metaheuristics with constraint programming approaches; combining metaheuristics with Machine Learning and Data Mining techniques [77].

Note that metaheuristics have an advantage over other methods, because they allow greater flexibility and adaptation to problems. As such, the basis of heuristics remains, but its modification or improvement is quite frequent, in order to meet the research conditions and to find optimal solutions [23].

From the range of papers that were analyzed, the authors choose different approaches, and it can be seen in the previous graphs (Figs. 1 and 2), that most focus on the use of populational metaheuristics.

\subsubsection{Non-populational metaheuristics}

Within non-populational metaheuristics and network reconfiguration, Hao et al. [26] adopt a non-populational strategy, using Variable Neighborhood Search (VNS), to which, as a startup method, it applies Branch Exchange 
(BE). The procedure is intended to allocate DGs as well as network reconfiguration. The combination of the methods aims to accelerate the research process and the quality of the solution obtained in the reconfiguration. In the first instance, when applying BE, the introduction of a new heuristic rule greatly reduces the number of candidate switches and computational complexity. As for the second phase and more specifically in the application of the VNS, a new neighborhood construction method is proposed, which aims to reduce the research space, as well as to prevent drops in local optimal.

\subsubsection{Populational metaheuristics}

3.4.2.1. Evolutionary algorithms. There are several application references of Genetic Algorithms (GA). This method has proven to be an effective tool in obtaining good optimum power distribution optimization. Traditionally and succinctly, the algorithm generates an initial population and later, according to a selection criterion, two individuals with the best characteristics that will represent the first generation of parents are chosen. This algorithm is characterized by the use of two operators - crossover (responsible for parent-child gene exchange) and mutation (responsible for adding diversity to the solutions).

The algorithm presented in [24], generates the initial population with a probabilistic selection method. In addition, it uses the elitism criterion for the selection of new parents, meaning that children with better fitness will be chosen as parents for the new generation. The need to maintain the assumption of radial network configuration is addressed here through a series of coding rules for individuals in the population, permitting only allowable solutions to be generated at startup and correcting non-allowable ones. The topology obtained in the initial generation may become inadmissible when mutation and crossover operators are performed; therefore, the authors make a change in the structure of the operators.

In turn, in [15], the authors use a parent selection method through a tournament technique and modify the crossover operator using the Kruskal Theorem and single loop information, to select which genes are to be exchanged. The mutation operator therefore randomly selects one or multiple previously obtained parent genes, forms the single loop by closing a branch in the corresponding tree (this single loop is created using a depth-fish graph search algorithm) and finally, one gene is randomly chosen again in this loop. In addition, the authors also establish the rate at which operators are executed through the sort-based adaptive algorithm, so that satisfactory convergence can be achieved.

Already in 2019, Kazemi-Robati and Sepasian are studying in [36] the design of anti-harmonic passive filters - a mechanism capable of reducing harmonic currents. The backward-forward sweep method is used for the calculation of harmonic load flows and the genetic algorithm is implemented for network reconfiguration. Antiharmonic passive filter plans should always consider the network configuration, otherwise they may obtain non-optimal solutions.

In the paper presented in [12], the authors apply the Biased Random Key Genetic Algorithm (BRKGA) in the network reconfiguration, presenting this as an optimization framework composed by two structures: the GA and the decoder. BRKGA differs from Random Key Genetic Algorithm (RKGA) in the way parents are selected for crossover execution. In the latter, they are randomly chosen from the population; in the former, a father is always chosen from the elite set, which introduces the principle of elitism in the reproduction process. RKGA differs from Genetic Algorithm (GA) in the matter of chromosome representation in that they are presented in RKGA by a vector of randomly generated real numbers (in a range between 0 and 1) called keys. Both BRKGA and RKGA are methods that search for solutions in a continuous n-dimensional hypercube unit, rather than directly in the research space. Thus, this requires coding in order to map the solutions in the hypercube (decoder). In [49], the authors allocate and scale a DSTATCOM device in the network, in addition to the normal reconfiguration process. Thus, in the device allocation phase, a fuzzy approach based on a loss sensitivity function is carried out, where the weakest nodes are chosen for the location. Subsequently, to determine sizing as well as perform reconfiguration, a GA is applied. Mohammadi, Abasi and Rozbahani prove that the chosen approach achieves better results only using GA. 
Still based on GA, Čadenović et al. [7] uses the cycle-breaking algorithms supported by adjacency matrices (AM) or elementary cycles (EC) integrated with GA operators in reconfiguration, which ensures the best exchange and survival genetic material through the process of evolution.

There are other approaches used by authors other than GA, most of them inspired by nature. For example, in [61] a modification of the Plant Growth Simulation Algorithm is used; which, as the name implies, is based on the plant growth process. This algorithm reflects the natural procedure, where initially the trunk of the plant root arises and later come the branches from its nodes, where concentrations of morphactin - substance responsible for plant growth - will be crucial. The authors refer that the modification of evolutionary algorithms is made to create a faster convergence, thus making them suitable for solving real problems. The modification of the algorithm consists only in setting a coefficient to a certain value, which is defined by the authors. In addition to reconfiguration, the allocation of DG mechanisms is considered and is based on sensitivity indexes.

In [62], a metaheuristic called Invase Weed Optimization is presented, where the objective functions, relative to the initial plants, are evaluated and ranked through a technique of choice of non-dominance. Each plant will give rise to a number of seeds depending on its position; as such, those with a better position (better objective function) will generate more seeds. In turn, the best seeds are "scattered" in the vicinity of current generation plants and integrated into the population. This procedure is iterative until a given population exceeds the maximum number of seeds possible. The population is again ranked, and according to its position is given a maximum number of seeds.

Nguyen et al. [53] apply a method based on the Cuckoo Search Algorithm - a recently proposed populational metaheuristic - to solve problems in reconfiguring power distribution networks. The authors report that compared to other methodologies, it has been more effective and has fewer control parameters, i.e. it is more flexible. The algorithm is inspired by the strategic reproduction of cuckoos. Essentially, the cuckoos lay their eggs in the nests of other bird species, and there is a risk that this species will realize that the eggs are not their own, destroying or abandoning them. Therefore, the best nests with the best egg quality will be those that will proceed to the next generation. As in nature, it is accepted that if the host bird leaves the egg (sensing that it is not its own), it will build a nest elsewhere, thus creating new locations for possible new nests. As the authors state, they adapt this problem with a specific input - DG - the greatest difficulty is to maintain the radial configuration of the network; in other words, in a first phase many inadmissible solutions will emerge. Therefore, they use graph theory to reduce the number of inadmissible solutions in each optimization phase. In a recent paper by Napis et al. [51], an approach is presented that adds to Particle Swarm Optimization (PSO) properties of evolutionary algorithms, giving rise to Improved Evolutionary Particle Swarm Optimization (IEPSO). The PSO fails to find an optimal solution as it tends to fall into optimal locations (premature convergence). Then the Swarm Intelligence algorithm (Sect. 3.4.2.2) in [51], applies evolutionary programming to increase the search ability of optimal solutions in a complex problem. The evolutionary process has selection processes that are based on the tournament schemes and this is used to select the ones best suited for the next generation. IEPSO is used for network reconfiguration; however, the authors still determine the optimal location of DG devices and for this, they use the sensitivity of the nodes for voltage collapse.

In addition to inspiration from nature, human behavior is also a focus on the part of researchers, and from it come two algorithms, Harmony Search Algorithm (HSA) and Imperialist Competitive Algorithm (ICA).

The HSA is based on the improvisation process of jazz musicians, which is employed by Yuvaraj et al. [86] in determining the local optimal and sizing of DSTATCOM, and by Kumar et al. [40] only in reconfiguring the network. Kumar et al. [40], in addition to metaheuristics, also uses a heuristic aimed at maximizing Node Voltage Quality Index (NVSI) and Node Voltage Quality Index (NVQI).

The ICA is used by Koong et al. [38] and is based on imperialist competition, where the population of individuals is defined as a country. This method is intended to perform network reconfiguration, DGs sizing and tap changer adjustment. These mechanisms are used to change the ratio of windings in a transformer. This change determines the voltage relationship between the windings and is essential for the stabilization of the mains voltage under variable load conditions. 
Finally, Rueda et al. [68] uses a search process that is developed with a normalized range of search spaces for all optimization variables, called Mean-Variance Mapping Optimization Algorithm, which aims to reconfigure the system. This method also has a file that acts as adaptive memory to record the $n$-best solutions so far.

3.4.2.2. Swarm Intelligence algorithms. Swarm Intelligence (SI) metaheuristics are the ones seen used the most by the authors and among them, the Particle Swarm Optimization (PSO) algorithm seems to be the most used.

The nature-inspired type of SI populational metaheuristics aims to convey the intelligent behaviors of homogeneous resource-sharing agents who adopt a community style as a metaphor for solving optimization problems. Arasteh et al. [3] shows that the PSO has several advantages over GA, such as greater improvement capacity, greater diversity and faster execution. Specifically, PSO focuses on the behavior of bird flocks. Assuming that a flock of birds randomly searches for food in a given area and that only a small amount of food is available, the strategy will be to follow the one at the shortest distance from the food. Thus, by adapting the foregoing and transporting it for reconfiguration of the power distribution network, a bird, also referred to as a particle, represents a solution. Initially a set of particles is generated and then each particle moves to a better location, while at the same time a velocity vector is created that stores the coordinates of the solutions (memory characteristic of the system) at each iteration algorithm). Finally, the one closest to the optimal solution is chosen.

However, Li and Xuefeng [42] and Pegado et al. [56] consider that the classical PSO is not suitable for solving combinatorial problems of pure discrete and binary nature. Therefore, the PSO is modified, using a new approach called Niche Binary Particle Swarm Optimization (NBPSO) whose application is based on network reconfiguration. In a first phase, the algorithm is adapted to the binary nature of the problem (BPSO). In a second phase, the proposed method creates niches within the particle population and first assesses the fitness of each niche, in order to mitigate the PSO's ability to rapidly converge. It then goes on to evaluate the best solutions in each of the niches and these will belong to the new particle population. The steps are executed successively until the defined stop criterion is met. Pegado et al. [56] inserts a modification of the sigmoid function in order to control the range of change of the particle vector, allowing a better exploration of the research space and a better convergence of the population.

Nevertheless, Subramaniyan et al. [73], based on the PSO, implements the Adaptive Weighted Improved Discrete Particle Swarm Optimization (AWIDPSO) algorithm for optimal reconfiguration, localization and sizing of DGs. In Discrete Particle Swarm Optimization (DPSO), the strategic balance between global and local research derives from a coefficient adjustment, while for IDPSO the weight of inertia is further adjusted. Here, the value of the inertial weight in the velocity increase equation decreases linearly from an initial value (wmax) to an ending value (wmin). With AWIDPSO, "w", which is the maximum inertial weight, is updated using an adaptive change strategy that is not only related to the number of iterations, but also to the dynamic performance of all particles. According to the authors, this algorithm improves population diversity.

Marjani et al. [66], which also aims to improve the voltage deviation index and maximize the power transmitted by the network, in addition to minimizing energy losses, and establishing a Multi-objective Particle Swarm Optimization (MOPSO) to address the different objectives. Following the implementation of this method for network reconfiguration, the authors bet on a Technique for Order Performance by Similarity to Ideal Solution (TOPSIS) procedure. After the output of Pareto solutions, it decides the best solution, taking into account two indexes: the preference and cost.

In addition to the PSO, other nature-inspired, community-based algorithms are implemented.

There are three papers $[25,52,64]$, that apply the Gray Wolf Optimization Algorithm (GWOA) to solve the reconfiguration problem; it is based on the natural behavior of alpha and beta gray wolves and uses processes of hunting, siege and attack to find better solutions. Nataraj et al. [52], present an algorithm that is a modification of GWOA, where they apply an exponential function to obtain a trade-off between exploration intensification and exploration intensification over iterations. Enlarging the former compared to the latter increases the speed of convergence and avoids the effect of getting stuck in great locations. Subsequently, Hamour et al. [25], present an approach that follows a similar perspective to [52]; however, the intensification of global exploration is broadened 
by changing the variation of one parameter from linear to non-linear. According to the authors, this change aims to avoid solution stagnation as well as reduce computational time.

Reddy et al. [63], Abdelaziz et al. [1,2] employ the Flower Pollination Algorithm (FPA), a method inspired by the task of flower pollination, the optimal location and sizing of devices. Abdelaziz et al. $[1,2]$ use indexes and loss sensitivity factors in determining the candidate nodes for the capacitor location; and for an effective location and sizing, they employ FPA. However, Reddy et al. [63] uses the DG units instead of capacitors, and bets on three types, with the aim to verify which one can achieve better energy loss reduction results.

Nguyen et al. [54] and Arasteh et al. [3] apply Runner Root Algorithm (RRA) to their problems, which is an algorithm that displays an analogy to the propagation behavior of certain plants. In [54] and with a view toward reconfiguration, daughter plants that are better than parent plants are selected to replace them and in order to reduce the number of candidates, all must be subjected to a fitness function (max-min), discarding those that do not meet all objectives. In [81], RRA is used in a first phase, for optimal location and sizing of DG devices, having to use the closed loop technique, and in a second phase for network reconfiguration.

On the other hand, Qi et al. $[58,59]$ opt for the Ant Colony Optimization (ACO) algorithm for network reconfiguration, which is based on the interaction between ants in a colony, where each ant is considered a solution that leaves a trace of pheromones. The amount of pheromone is directly proportional to the quality of the solution and as the pheromone disappears over time, a shorter path is formed. The transition of "ants" between us on each path, is made through a probabilistic selection rule. In a given period the best solution is the one that has the largest amount of pheromones. In addition to reconfiguration, both papers introduce SOP (Soft Open Points) in their network and use taxy-cab as a method of adjusting the output of these mechanisms.

In [78], the authors use a modified version of the Group Search Algorithm, which portrays the behavior of animal groups, like the other SI metaheuristics. This method focuses on the animal search action, where each population is named by group and each individual by member. In this symbiosis there are 3 types of members, called producers, scroungers and rangers. The metaheuristic presents a modification in relation to the coding, in order to adapt the problem to its binary nature and evaluates at each iteration the radial topology of the network.

In 2014, LakshmiReddy et al., state in [41] that although GA and PSO algorithms achieve appropriate results in several optimization problems, in practice their application is limited because both have a high dependence on the initial parameters adjustment. This makes the likelihood of getting stuck in a local optimal increase. Alternatively, they present a new algorithm - Firefly Algorithm (FA) - a populational metaheuristic based on firefly behavior and brightness. Each firefly will be placed in an initial state and travel a path to the final state using a random proportional rule, which will eventually favor the transition state for nodes that are connected through shorter edges with high amount of pheromone.

Imran and Kowsalya [27] is inspired by a stochastic technique based on fireworks explosions, which are eventually considered the research space. This technique is called Firework Algorithm (FWA) and is implemented in network reconfiguration. They are then initially "launched" randomly into the solution space at the spark locations. In order to maintain diversity, an explosion coefficient based on the Gaussian distribution is applied to some sparks. It should be noted that the research process used in FWA incorporates the structure of existing heuristic methods, preserving the best location that is reasonably close to the desired optimum. Additionally, there is a selection of the locations of the two types of sparks which are generated with some probability, for the next generation of explosion. These particularities make the algorithm unique and with greater convergence capacity when compared to GA, which only considers the generation of new locations through two others (the parents). In addition, FWA assumes the independence of each dimension of a site while generating a new location for sparks, something that cannot happen in GA, since the structure of the gene must be maintained.

Regarding the integration of heuristic methods and electronic devices, Devabalaji and Ravi [14] and Yuvaraj et al. [87] include DSTATCOM in their formulations, but Devabalaji and Ravi [14] goes a little further and also seeks to include DG devices. It starts by implementing a loss sensitivity factor to determine the initial location of the devices. Afterward, optimal allocation and sizing is found through the Bacterial Foraging Optimization Algorithm (BFOA), based on the law of evolution that supports the species with the best food searching 
capability. These species are capable of producing better species in the future and their propagation in the evolutionary chain is then facilitated. Particularly, Yuvaraj et al. [87] simply attempts to find the optimum location for DSTATCOM; for that, they start by calculating a voltage stability index on the nodes to determine the location, and then employ the Bat Algorithm (BA) in the resolution in finding the optimal dimension for this device. BA is inspired by the behavior of bats, more specifically their echolocation ability to detect objects around them.

In the same order of ideas and still within the integration of the two methods, Reddy et al. [65], Onlam et al. [55] and Nguyen et al. [54] opt for the introduction of DGs; however, each selects the most convenient algorithm for their formulations. Reddy et al. [65] uses the energy loss index to determine the optimal location of the mechanisms, while its design uses the Whale Optimization Algorithm (WOA), a method inspired by the unique hunting behavior of humpback whales. Onlam et al. [55] is based on the Shuffled Frogs Leaping Algorithm (SFLA) for the reconfiguration and allocation of DGs, whose inspiration lies in imitating the frog's food-seeking culture by sitting randomly in the pond. Thus, the evolution of a response is acquired by switching groups of frogs within a single pond as well as between lakes. However, Onlam et al. [55] elaborates on this method an adaptive strategy (Adaptive Shuffled Frogs Leaping Algorithm - ASFLA) whose objective is to improve the process of generation and research of the original algorithm. Tolabi et al. [80] in turn organizes its process into two phases, the first of which is dedicated to locating devices using the Improved Analytical Method (IAM) to reduce search space. In the second phase, for the reconfiguration and identification of the optimal capacity for the installation of the DG mechanisms, it uses Bees Algorithm (BA), an algorithm that mimics the behavior of bees in search of food. This behavior is based on the ability of these flying beings to travel over long distances in conjunction with multiple directions, where places with a larger portion of nectar will prove to have more bees. Since Tolabi et al. [80] wishes to improve several objectives simultaneously a fuzzy environment is applied by transforming the variables into a range of values between 0 and 1 .

3.4.2.3. Other populational algorithms. Artificial Immune System (AIS) algorithms are populational, but unlike the previously analyzed methods, they are inspired by the behavior of immune systems. Since the biological immune system is highly robust and adaptive and has great learning and memory capacities, this leads to its application in optimization and machine learning problems more frequently. In the context of optimization problems, the most commonly reported AIS in the literature are Clonal Selection Algorithm (CLONALG), Artificial Immune Network (aiNet), Opt-aiNEt, B-cell (BCA) and Copt-aiNEt.

In [72], Souza et al. apply an AIS via Copt-aiNet, an extension of the original aiNet in the reconfiguration process. In the same article, specific coding is used to ensure that the initial population admits only radial topologies and search operators are developed to preserve this configuration.

Also in [71], Copt-aiNet is implemented, as is Opt-aiNet. These two approaches are suggested for the reconfiguration procedure and the second differs from the first in terms of cloning processes, maturity affinity, dynamic population size and elitist selection. Apparently, Copt-aiNet achieves the solution in fewer iterations and in less computational time, this is due to the mutation processes that make the search more intensive.

In [75], to optimize the location and sizing of the DSTATCOM device, Taher and Afsari use the Immune Algorithm (IA). The algorithm used is inspired by the procedure of the immune system response to invading agents through the production of antibodies.

In addition to AIS algorithms, there are authors who use intelligent procedures, such as the Teaching Learning Based Optimization Method (TLBO), which consists of two phases, which is based on the teaching method in a class. The first is in the teaching phase (students learn through the teacher) and the second in the learning phase (students learn from each other). Kanwar et al. [33] applies this base algorithm in reconfiguring and allocating DGs. While Lotfipour and Afrakhte [46] modifies the base algorithm to one capable of handling discrete problems and uses it in reconfiguring and allocating DG devices. Finally, Kanwar et al. [34] adds to TLBO a more selective and more diverse learning by applying the GA crossover and the entire procedure to the reconfiguration, along with the installation of parallel capacitors and DGs. 
Another algorithm considered intelligent is the Lightning Search Algorithm (LSA), used by Thangaraj and Kuppan [79] to solve the problem of allocation of DGs and DSTATCOM simultaneously. The method is inspired by the common thunder phenomenon and is applied to a multi-objective system solved by weighting.

With the advancement of research in the context of the reconfiguration of power distribution networks, some limitations in the classical methods are becoming evident; thus, the necessity of complementing techniques, adding strengths from other procedures to achieve better and more reliable results from a practical point of view. Hence the appearance of junctions of different methodologies from heuristics and metaheuristics, but also exact algorithms and methods, which are called hybrid methods.

\subsubsection{Hybrid metaheuristics}

The Big-Bang-Big-Crunch Algorithm was introduced in 2006, based on the theory of evolution of the universe. Being a local search method and simple to implement, its application to optimization problems proved to be very effective, as it has low computational times and a high convergence speed. However, and despite this, gaps in terms of overall algorithm research were found and, in order to bridge them, researchers added PSO characteristics to this technique, thus developing a hybrid metaheuristic [17,69]. In these works, the authors use Hybrid Big Bang-Big Crunch (HBB-BC) in conjunction with PSO adapted to a multi-objective formulation, to perform a network reconfiguration, as well as the allocation of DG devices. In HBB-BC, three parameters from the previous iteration are used for each solution: the center of mass, the best position and the best overall position. Esmaeili et al. [17] uses a fuzzy technique (improves exploitability and ensures a greater diversity of Pareto solutions) to select the best solutions and models the uncertainty of loads through the Triangular Fuzzy Number concept. Sedighizadeh et al. [69] also carries out a fuzzy method when joining the various objective functions and normalizes it by switching to a range between 0 and 1, which guarantees shorter computational time.

Azizivahed et al. [4] combine Shuffled Frog Leaping Algorithm (SFLA) with Particle Swarm Optimization (PSO) for the reconfiguration and allocation of DG mechanisms, as seen in [17,69]. The authors, in both papers, consider that the proposed method is a strong combination of mutation operators, since the original algorithms have a premature convergence. This junction aims to increase population diversity and streamline research. Thus, in [4], the algorithms will be executed separately, and each iteration compares the best solutions of each algorithm, being the best used by both in the next iteration. In [4] the SFLA adds a strong mutation operator, creating a new version of the algorithm, called Modified Shuffled Frog Leaping (MSFL) by the authors. They add PSO to the MSFL to increase population diversity, improving search capability in the solution space.

In their work [18], the authors use the 3-layer Artificial Neural Network (ANN) algorithm for distribution network reconfiguration, to obtain an optimal configuration (which minimizes energy losses). This method is widely used in optimization problems. However, in [18], a modified dynamic Fuzzy C-Means (dFCM) algorithm based on the formation of clusters with good characteristics is used in order to reduce the complexity of the previously obtained network. This allows the computational time to be significantly reduced, the network structure to become simpler and the results to be more accurate when compared to other approaches. Similarly, in [50] a hybrid approach is applied using the ANN-based Radial Basis Function Network (RBFN) and Classification and Regression Trees (CART) a Data Mining method. The RBFN is a linear function, approximated by a set of other radial based functions where the weights of the "neurons" (representing the nodes of the network) are evaluated by a learning process (AI). Here CART is used to improve the quality of information read by RBFN. Essentially, it is possible to process and prepare the data through the CART technique, thus minimizing the solutions that RBFN will evaluate. Thus, the computation time is minimized, a fact proven by the authors comparing the time values obtained only by the RBFN, concluding that this combination is useful from the point of view of the computational time reduction.

Ma et al. [47] uses the BPSO in two ways, for reconfiguration and for the allocation of DG units. In the research phase within branch groups, the authors prefer the use of Improved Binary Particle Swarm Optimization (IBPSO) to the use of BPSO in its most basic form. IBPSO differs from the BPSO standard through the 
probability mapping function, allowing a significant improvement in the local search capability, thus contributing to higher efficiency.

In 2017, Fathy et al. [19] aggregate the PSO with Gravity Search Algorithm (GSA), but only for network reconfiguration. The integration of these two algorithms aims to overcome and compensate for the weaknesses of each. In PSO, the position of each particle is updated by a sigmoid function, which leads to erroneous estimates of the best position of each particle. Additionally, the update process does not depend on the previous solution. On the other hand, the local search in final iterations by GSA is slow.

There is a work by Kaveh et al. from 2018 [35], which focuses on reconfiguring and allocating DGs in the network and for this purpose combines the Bacterial Foraging Optimization Algorithm (BFOA) with the Spiral Dynamic Algorithm, the latter intended to accelerate the convergence of the first method. This junction of algorithms is also applied to the realization of a rehash process. This need is due to the presence of different types of loads and seasonal loads, which can lead to network imbalance. This procedure can transfer loads to other phases, so that the network is more balanced and is performed through two strategies, positive sequence and negative sequence.

Ganesh and Kanimozhi [20] presents the Multi-Objective Modified Flower Pollination Algorithm (MO-MFPA) process, which is based on the integration of the standard Flower Pollination Algorithm (FPA) algorithm with the Clonal Selection Algorithm (CSA). The merging of FPA with CSA intends to make use of the clonal property inspired by the clonal selection principle of the second method. To deal with the various objectives, the authors resort to Pareto solutions that are later manipulated by a TOPSIS method for the final decision.

In [82], the Modified Culture Algorithm (MCA) is presented for the reconfiguration of the network. This algorithm results from the merging of Culture Algorithm (CA) with Genetic Algorithm (GA), with the purpose of MCA containing the operators of both metaheuristics. CA is a meta-heuristic where each individual in the population is characterized by psychological traits that can change according to social behavior and individual experiences. This all happens in what the authors call belief space. This space must be better from generation to generation, otherwise it is discarded. In addition to the GA crossover, mutation and reproduction operators, we have two more, belief space and communication protocol, which are already CA features.

\section{OBjeCtive FUnCtion}

During the study, it was found that the objective function that the authors use most often is the minimization of energy losses - O1 (Tab. 1). However, these losses are mostly associated with those of active energy, with no great consideration for reactive energy. The second most considered objective function is the requirement for the stress profile improvement $(\mathrm{O} 2)$, which is often associated with the minimization of the total stress deviation index. Next, and more or less balanced, we find the total cost minimization (O5), closely associated with energy losses, the branch load index minimization (O8 - LBI) and the maximization of the voltage stability index (O16). - VSI: Voltage Stability Index.

In Table 1, the number of papers (in terms of absolute values) that use each of the objective functions is presented. Also presented is the number of times each objective function is used (Relative \%) in the 90 papers that were analysed.

\subsection{Multi-objective problems}

Regarding the objective functions, one can easily verify the existence of two large groups, the mono-objective and multi-objective (MO) problems. The optimal solution to formulated problems like MO is not a single solution, but a set of solutions. This set represents a compromise between the different objectives that may enter into conflict with each other. Thus, the best solution is not defined as single-objective algorithms, but as the best combination of various objectives, and the last decision is always up to the decision maker [77]. Although exact algorithms are applied to solve MO problems, they are only effective for small problems. In recent years, the application of metaheuristics in MO problems has intensified. Hybrid metaheuristics can be 
TABLE 1. Objective functions.

\begin{tabular}{|c|c|c|}
\hline \multirow[b]{2}{*}{ Objective functions } & \multicolumn{2}{|c|}{$\mathrm{N}^{\circ}$ of Papers (2003-2019): 90} \\
\hline & Absolute & Relative (\%) \\
\hline O1 - Minimize energy losses & 63 & 74.1 \\
\hline O2 - Minimize Total voltage deviation index / Maximize voltage profile index & 18 & 21.2 \\
\hline O3 - Minimize Fi (Average system interrupt frequency index) & 2 & 2.4 \\
\hline O4 - Minimize ENSi (energy not supplied by candidate topology) & 2 & 2.4 \\
\hline O5 - Minimize Total Cost & 11 & 12.9 \\
\hline O6 - Minimize total emissions & 3 & 3.5 \\
\hline O7 - Minimize number of switch state change operations & 4 & 4.7 \\
\hline O8 - Minimize branch load balancing index (LBI) & 7 & 8.2 \\
\hline O9 - Minimize load balancing feeder index (LBF) & 3 & 3.5 \\
\hline O10 - Maximize DGs penetration level & 2 & 2.4 \\
\hline O11 - Minimize Energy Loss Costs & 5 & 5.9 \\
\hline O12 - Minimize operating costs of switch state changes & 2 & 2.4 \\
\hline O13 - Maximize cost-effective voltage profile improvement & 1 & 1.2 \\
\hline O14 - Minimize Ti (inaccessibility index) & 2 & 2.4 \\
\hline O15 - Minimize average outage duration index & 1 & 1.2 \\
\hline O16 - Maximize stress stability index & 8 & 9.4 \\
\hline O17 - Minimize maximum voltage deviation at nodes & 2 & 2.4 \\
\hline O18 - Minimize DSTATCOM Dimension & 1 & 1.2 \\
\hline O19 - Maximize network hosting capacity of DGs & 3 & 3.5 \\
\hline O20 - Line utilization balancing & 1 & 1.2 \\
\hline O21 - Minimization of customer interruption costs & 1 & 1.2 \\
\hline O22 - Maximize power transmitted in the network by one factor for each node & 1 & 1.2 \\
\hline O23 - Minimize minimum network load index & 1 & 1.2 \\
\hline
\end{tabular}

used to solve problems that consider more than one objective, and the right combination of concepts from different metaheuristics can increase efficiency and flexibility when dealing with large real problems [77].

Problems of an MO nature can be addressed by the Pareto solution method or the weights method, when analyzing results and in cases of Multi-criteria problems. In the case of the Pareto principle-based method, the number of optimal solutions increases according to the problem and the number of objectives to be considered. While mono-objective problems lead to a single global optimal solution, a multi-objective problem may have a set of solutions known as Pareto-optimal set [44]. In this method, Pareto-optimal set or Pareto-optimal frontier can be obtained through classification algorithms that evaluate the candidate solutions. The biggest advantage of using this method, with an articulation of preferences after the fact, is to give equal attention to the different objectives. If there is no additional information about the importance of each objective, all Pareto optimal solutions are equally important. In practice the decision maker defines the best solution to be used at the moment, taking into account three goals in MO optimization [77]:

(1) find a set of solutions that are as close as possible to the Pareto Border;

(2) find a set of solutions as diverse as possible;

(3) accomplish the two previous goals as efficiently as possible.

In the weights (or multi-criteria) method the various objectives are transformed into a single objective through the weight coefficients given to each of them. Several approaches can be taken to determine these coefficients, as follows:

- the fixed weight assigned by the decision maker;

- the process of analytical hierarchy;

- stochastic weights; 
- random mathematical methods;

- among others.

These weight coefficients are a preference made in advanced, with the advantage of simplicity and convenience, but on the other hand with the disadvantage of subjectivity [44]. Nineteen papers were analysed (Tab. 2), and a comparative analysis of the different multi-objective approaches was made. Depending on the paper, the following objectives were combined:

- PL Power losses.

- TVD Total voltage deviation.

- IF Average interruption frequency index.

- VSI Voltage stability index.

- VPI Voltage profile improvement.

- Ii Inaccessibility index.

- ENSi Index of energy not supplied by the candidate topology.

- NSW Number of switching.

- CT Total cost.

- ET Total emissions.

- LBI Load balancing among the branches.

- LBF Load balancing among the feeders.

All the nineteen papers were analyzed and categorized in terms of: Objective function combination, individual results achieved by each approach, energy losses in the initial structure, percentage of energy loss reduction from the various approaches, and CPU time and implementation general information. In comparative terms, by analysing Table 2 , it is clear that we can only compare the approaches presented in $[53,55]$. The first paper presents an evolutionary Populational approach and the second uses Particle swarm optimization. However, both use the same combinations of goals and the same combination of electronic devices and the same way to reduce energy losses and costs (Network reconfiguration, installation, location and reconfiguration of DGs). Thus, in these two cases we can conclude that paper [55] achieves on average a greater reduction in power losses than with [53]: $65.76 \%-62.76 \%$. However, we can also compare it to [51] which, for the same purposes and in a network reconfiguration situation, achieves a $23.26 \%$ reduction in energy loss, compared to $30.94 \%$ from $[53,55]$. In relation with the energy losses in the initial structure, all three approaches has the same values. The only available information related to the computational time is for [51], which is only $6.17 \mathrm{~s}$. Looking to all the others approaches, the computational time is always small, in most cases it being less than one minute.

\section{Constraints}

In order to ensure the reliability of the solutions obtained by the various approaches, each work assumes a set of constraints in the modelling of its problem. The constraints considered in each of the analysed papers were done so in order to understand which are the most prevalent. Of the analysed papers, most consider five technical constraints:

- maintenance of the radial network;

- limits of the magnitude of the tension in the nodes;

- limits of branch capacity (may be power or current intensity);

- energy conservation equations, ensuring that the energy injected into the network by the feeders is that required by the nodes;

- operational limits of DG devices (thus revealing that the introduction of such mechanisms in the network is already a concern of researchers and tends to evolve).

Table 3 shows the number of papers (in terms of absolute values) using each of the constraints. It also presents the number of times each constraint is used (Relative \%) in the 90 papers that were analysed.

Authors who do not consider the constraint on the radial network $(\mathrm{C} 1)$, assure it when solving the problem through the approach they use. Regarding the remaining constraints, these appear to support the type of 


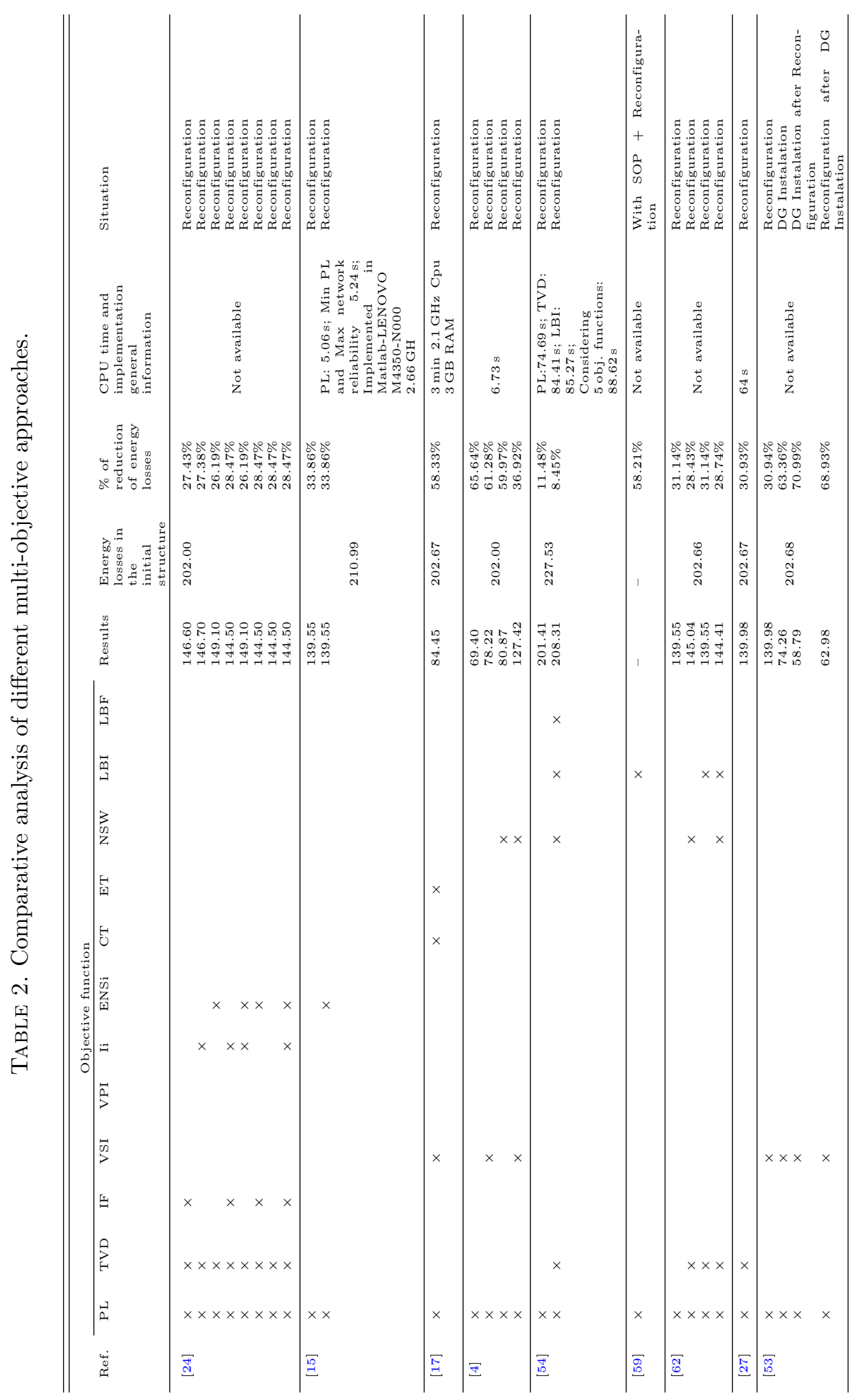




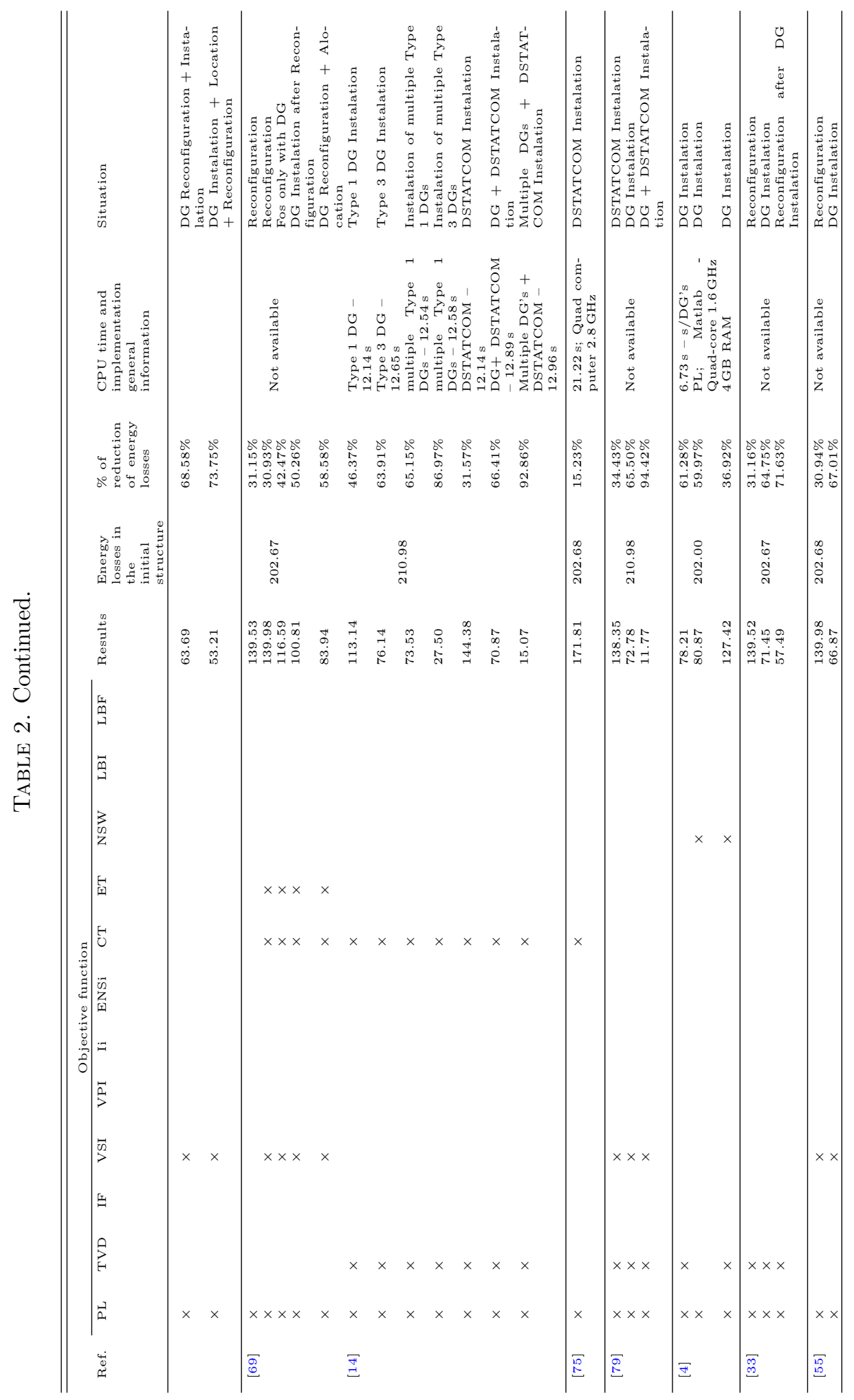




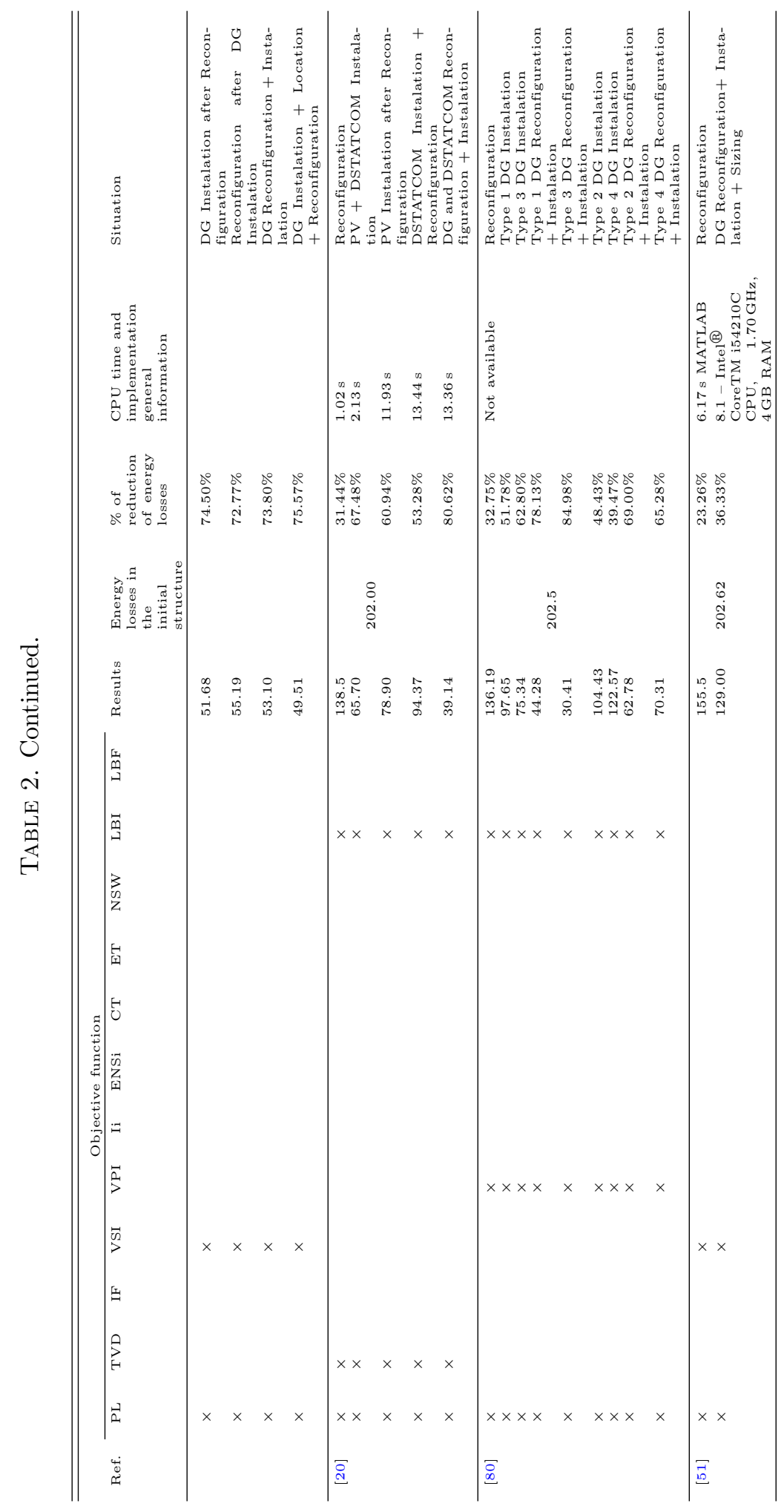


TABLE 3. Type of constraints.

\begin{tabular}{lll}
\hline \hline & \multicolumn{2}{l}{$\mathrm{N}^{\circ}$ of Papers (2003-2019): 90 } \\
\cline { 2 - 3 } Type of constraint & Absolute & Relative (\%) \\
\hline C1 - Maintain radial network & 51 & 60.0 \\
C2 - Voltage limits at the respective network nodes & 69 & 81.2 \\
C3 - Limits of branch capacity (power / current intensity) & 55 & 64.7 \\
C4 - Network energy balance equations & 46 & 54.1 \\
C5 - Kirchhoff current and voltage laws & 3 & 3.5 \\
C6 - DGs operational limits & 20 & 23.5 \\
C7 - Penetration level of DGs & 2 & 2.4 \\
C8 - Network connectivity restriction & 6 & 7.1 \\
C9 - No feeder shall be out of service. & 1 & 1.2 \\
C10 - Soft Open Points (SOP) specific constraints & 5 & 5.9 \\
C11 - Demand Response (DR) program constraints & 1 & 1.2 \\
C12 - Binary condition for maneuverable switches & 1 & 1.2 \\
C13 - Active power loss in branches at load level $u$ & 2 & 2.4 \\
C14 - Active power losses in all branches & 1 & 1.2 \\
C15 - Compensation of real or reactive energy in nodes & 6 & 7.1 \\
C16 - Limits for total harmonic distortion & 1 & 1.2 \\
C17 - Node filter limit & 1 & 1.2 \\
C18 - Binary condition & 1 & 1.2 \\
C19 - Energization of all nodes & 4 & 4.7 \\
C20 - Substance capacity limits & 5 & 5.9 \\
C21 - Demand flexibility & 1 & 1.2 \\
C22 - Switching operation constraints & 2 & 2.4 \\
C23 - Limits for DSTATCOM & 1 & 1.2 \\
C24 - Voltage drop equations & 1 & 1.2 \\
\hline
\end{tabular}

proposed algorithm or the introduction of other mechanisms that were previously revealed. Of the 90 analyzed studies (Tab. 3), there are 5 technical constraints that are the most used, namely: the maintenance of the radial network, limits on the magnitude of the node tension, limits on the capacity of the branches, equations of energy conservation, ensuring that the energy injected into the network by the feeders is what the nodes require and, finally, the operating limits of the DGs.

\section{Startup methods, Stop CRiteria, And COMputational time}

Faced with a NP-Hard combinatorial optimization problem, whose main objective is to achieve good results in a short time, the initialization methods and the stop criteria adopted in the different approaches are of great importance; these are closely linked to the computational time required in the execution of the algorithm. In all the studies in this paper, heuristics, metaheuristics and hybrid approaches have been used, but promising results may be compromised by the initial chosen solution. This is because regardless of the approach, the quality of the final solution and the computational time required to achieve it will depend heavily on the quality of the initial solution.

In the case of non-populational metaheuristics, this initialization can be generated either randomly or using a greedy method. Random initialization is generally a faster procedure, but metaheuristics may require more iterations to converge. On the other hand, when using a greedy method can help in the search process, making it more efficient and thus finding a better local optimal.

In populational metaheuristics the initial population diversification plays a major role in the efficiency as well as the effectiveness of the algorithm; however, the computational cost increases. That said, if the initial 


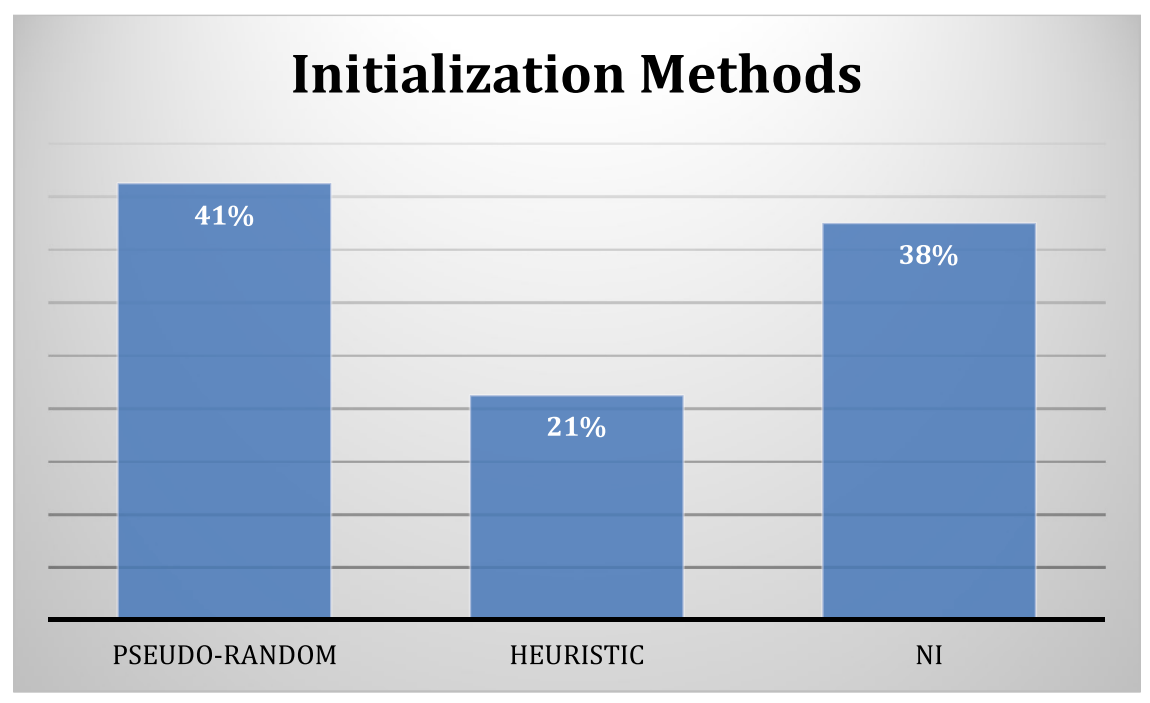

Figure 4. Initialization Methods.

population is not sufficiently diverse, the likelihood of converging prematurely increases exponentially. The use of a heuristic in the initial population generation may be a possibility, and it will create higher quality initial solutions with a lower computational cost, but they will have less diversification. A pseudo-random strategy will increase diversification, but with a higher computational cost and lower quality of initial solutions [23].

In this paper, the initialization methods were classified as random or pseudorandom or as heuristic procedures, the latter being related to a given method not included in the first two and which is adapted by the author considering other considerations.

Figure 4 presents the percentage distribution of the different initialization methods used in 80 of the analyzed papers. From its analysis, it is clear that the most commonly used initialization method is pseudo-randomization, especially in populational algorithms, thus ensuring the diversification of the initial population. However, some authors prefer to start their approaches through the use of heuristics or even to use heuristic methods as an approach to solve the proposed problem. This fact is generally related to a better computational time compared to those who choose the pseudorandom process.

The NI (Fig. 4) column represents works whose startup method has not been identified.

As for the stop criteria, these can be divided into two large groups, static procedures or adaptive procedures. The great difference between them is related to their prior knowledge of the end of the research, since in the static procedures this end is known, but not in the adaptive procedures. An example for the first would be to establish a fixed number of iterations, while for the second would be to establish a fixed number of iterations without improving the objective function. In Figure 5, the percentages of utilization of the various types of stop criteria used in the 80 presented papers.

As for the stop criterion, the most used is presented as the definition of the maximum iterations to be performed by the algorithm; in other words, the static criterion in $45 \%$ of the papers. Only $19 \%$ of these use dynamic stop criteria. However, $11 \%$ of the approaches use a combination of the two criteria (Mix). The stop criteria are not identified in $25 \%$ of the papers. The static stop criterion is used in approaches where the initialization is made through pseudorandom methods. Thus, it can be assumed that the stop criterion - the maximum number of iterations - is the most viable when the computational time of pseudo-randomly initialized algorithms is to be reduced. This finding is true for all the papers that were analysed and have information on computational times. Papers where quantitative computational times are not presented, claim to have come 


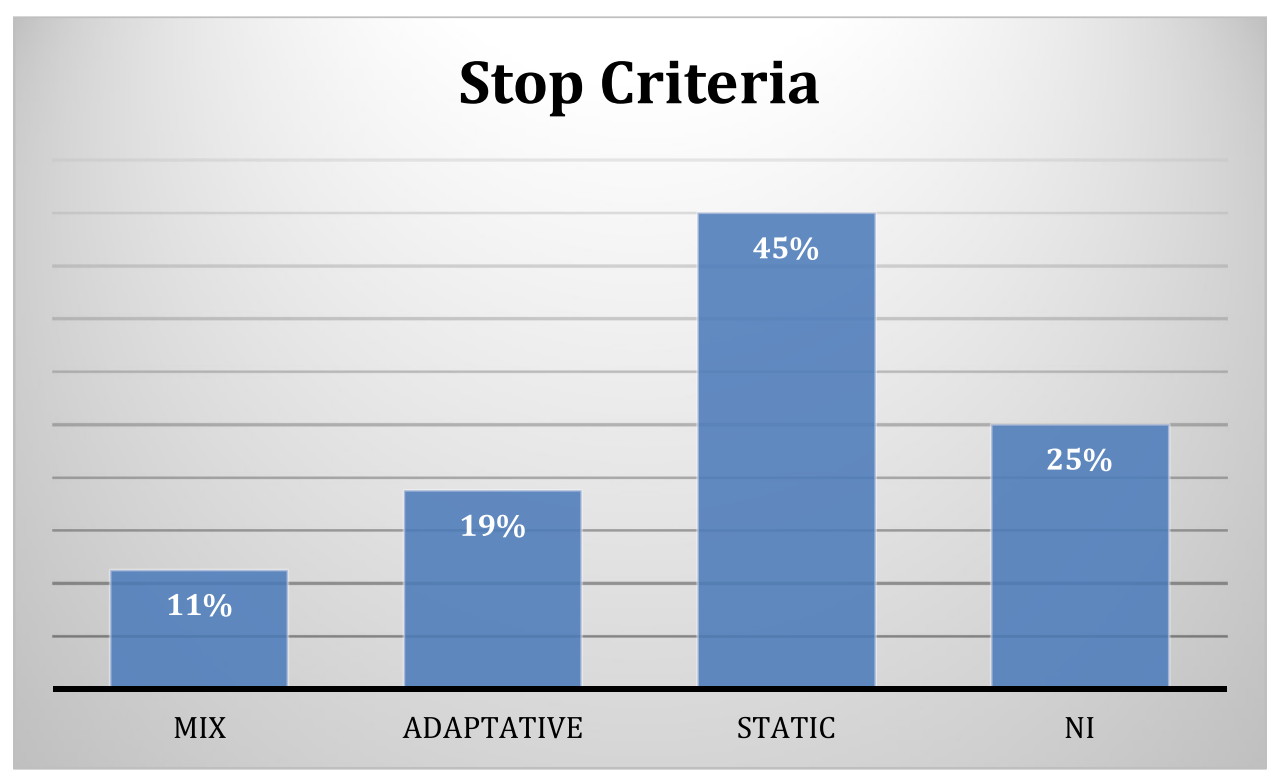

FIgURE 5. Stop criteria.

up with a solution in reasonable and feasible times and warn of the great capacity of their approaches for reconfiguring electrical distribution networks.

\section{Comparative analysis and CONClusions}

In the present work a comparative analysis was made in terms of approaches, to solve the problem of reconfiguration of power distribution networks (33-bus). For this, a study of 90 papers published between 2003 and 2019 was performed. Several reconfigurations techniques used in distribution networks literature were studied in this paper. Different practical aspects to deal with the reconfiguration problem, such as load representation, DG's and storage units, has been presented. In order to introduce and better explain the problem, a general mathematical formulation was also presented, where the objective is to minimize the power losses. Several other formulations could be made, depending on the problem that one wants to solve or present. Other objectives can be added to the main objective function, such as the reduction of switching operations, total voltage deviation or the total cost, etc..

\subsection{Comparative analysis}

The most used objective was the minimization of energy losses and the problem approached as a monoobjective. In general, the results are very similar in terms of percentage of energy loss reduction for the different papers when not considering device allocation in the network structure. The higher value was $38 \%$ in reductions, corresponding to [25], where the authors use a population algorithm inspired by the behavior of alpha and beta gray wolves.

Since this overview has been demonstrated, a possible conclusion to be drawn is that heuristic initialization, while not guaranteeing high quality initial solutions, guarantees equally satisfactory results when compared to initializations using pseudorandom processes. Also, these same results are obtained globally with a shorter computational time.

However, when devices are introduced to the network, the values change. The introduction of only DSTATCOM does not imply a significant reduction in power losses; however, when this type of mechanism is combined 
with the network reconfiguration the values increase considerably. The same is true for the introduction of DGs or SOPs, and in the first case, the type of mechanism (1,2,3 or 4) has a strong impact, highlighting type 3, which as mentioned above, can control active and reactive power in the network. In most cases where they are considered DGs or SOP, their simultaneous reconfiguration installation appears to achieve greater reductions in energy losses than when considering only the installation of DGs or SOPs, or their installation before or after reconfiguration through the proposed algorithm.

It should be noted that when combining mechanisms, the results are even more promising. Devabalaji and Ravi [14] do just that and have the biggest reduction of energy losses, $88.71 \%$, by introducing capacitors and DGs, where reconfiguration is applied in the first phase using Dedicated Search Teaching Based Optimization (DSTLBO), and in a second phase the optimum installation of device efficiency results.

Note that only in papers: $[5,13,22,33,34,38,40,41,71,72,78,86,87]$, is the uncertainty of loads considered in their procedures, a factor that makes the evaluation of the problem more realistic. In turn, Table 2 presents the works that consider multi-objective approaches. Generally, the higher the number of objectives, the more the percentage of energy loss reduction is decreased. However, in a multi-objective analysis there is no guarantee that one will achieve the optimal solution, unlike with mono-objective approaches, that depend on the decision maker and the criteria used in the decision-making process. Yet, the conclusions drawn in the mono-objective device analysis remain with a multi-objective approach.

The results obtained by Thangaraj and Kuppan [79] are noteworthy, because the energy loss reduction reaches $94.4 \%$, considering a multi-objective function. In this case, the objectives considered are the maximization of energy losses, the minimization of total voltage deviations and the maximization of voltage stability. It should be noted that a weighting was made for each of the objectives, defined by the authors according to their experience and taking into account that energy losses have a certain priority over the others. This has a bearing on the results because if different weights are chosen, the solution may also be different. In this paper, a recent meta-heuristic, Lightning Search Algorithm (LSA), is presented to solve the problem of allocation (location and size) of DGs and D-STATCOM simultaneously in the distribution system. The algorithm is inspired by nature and tries to portray the projection of particles during a thunderstorm, specifically the occurrence of lightning. In [79], we also compare results from other studies, concluding that this algorithm is more effective than the Bacterial Foraging Optimization Algorithm (BFOA) and Quasi-Oppositional Teaching Learning Based Optimization (QOTBLO) regarding DSTATCOM allocation, and then the Backtracking Spiral Algorithm (BSA) regarding the allocation of DGs.

Since no other study has an objective function with the same combination of criteria, it is not possible to compare results with other authors. However, it is noted that for works that consider a mono-objective, the technique used has a great impact on the results. High levels of loss reduction occur in the allocation of DGs and D-STATCOM, and [79] does not even consider network reconfiguration.

\subsection{Conclusions}

Reconfiguring power networks is a proven efficient technique for optimizing said networks. Over the last decades, several authors have been investigating new approaches to reconfiguration, some based on mathematical and deterministic models, others on more practical techniques and on heuristics and metaheuristics. The latter have been evidenced and present promising results, with a good compromise between the obtained solutions and the corresponding computational time.

In the present work, the most recent existing papers on this subject were analyzed, taking into account the approaches taken by the authors, the formulation of the problem - namely its objective functions, constraints, start and stop methods - as well as the results taking into account the reduction of energy losses achieved by the authors' tests on 33-bus systems.

Regarding the analysed methodologies, it is concluded that there is no single recipe to address this theme. The authors choose different approaches, from evolutionary populational metaheuristics such as GA, PGSA, Swarm Intelligence metaheuristics, hybrid metaheuristics, to constructive heuristics. Although some results are better in a similar simulation context, the differences between the results are not so significant that one approach 
can be defined as the most correct. In other words, some methodologies may be better suited and better solved in one problem that considers a given set of constraints than in another with a different set of constraints.

Moreover, in situations where the context of simulation varies (when some authors consider DGs, others SOPs or DSTATCOM), the results are also different according to the technology they adopt. Load uncertainty is taken into account in a small percentage of the analysed studies, which is essential when introducing the method in a more real context.

Reactive energy losses is another factor considered by the authors to be of little relevance, but would be important in a real world context, as they prove to be major agents in industrial energy management with a strong impact on costs. In addition, and due to the pressing need to introduce renewable energy, DG devices should be considered a strongly and in order to increase their penetration in the network, the combination of Soft Open Points in the network is a possibility.

That said, one of the contributions of this study is presented in the attached table (Appendix A), which compiles the advantages and disadvantages of each technique presented by each of the papers that were analyzed. This is a way of summarizing what really stands out in each article and what does or doesn't contribute to a more thorough research and comparative analysis. However, as a general conclusion, it was found that:

- In general, heuristic methods are associated with lower computational times.

- For pseudorandom methods, the most commonly used stop criterion is the maximum number of iterations.

- Regarding the objective function: minimization of energy losses; the values are around $30 \%$ reduction when considering only reconfiguration, and therefore the fact that some authors start with heuristic methods and others with pseudorandom methods has no major impact.

- However, the results all change when we add DG systems. The results with these units reveal reduction values of around $70 \%$.

- When still adding to the reconfiguration and DGs, Soft Open Points or D-STATCOM, they can achieve a reduction of $80 \%$ in energy losses.

However, the growing technological evolution already allows for the creation of Smart grids, a series of integrated technologies, methodologies and procedures for planning and operating in power networks. The information and functionality of remotely controlled equipment that is installed on the distribution systems can be used and manipulated in a computerized system. This allows for real-time network reconfiguration (one of the disclosed software is called SCADA) [57].

It is therefore assumed that integrating the choice of a superior technique both effectively and efficiently with the development of automation, internet of things (IoT) and artificial intelligence (AI), could revolutionize the way we view the reconfiguration of power distribution networks.

\section{Appendix A. Advantages and disadvantages of the various techniques PRESENTED}

\begin{tabular}{|c|c|c|}
\hline References & Advantages & Disadvantages \\
\hline \multirow[t]{2}{*}[61]{} & $\begin{array}{l}\text { Considers DG mechanisms. } \\
\text { Allocate the DGs using a sensitivity index. } \\
\text { MPGSA is considered more suitable for use in } \\
\text { real context, as it is more practical as objec- } \\
\text { tives and constraints are dealt with separately. }\end{array}$ & $\begin{array}{l}\text { Does not consider load uncertainty, although } \\
\text { it states that the method used (MPSGA) is } \\
\text { capable of dealing with this phenomenon and } \\
\text { can therefore be used in real context. }\end{array}$ \\
\hline & $\begin{array}{l}\text { Reveals better performance over GA, Refined } \\
\text { Genetic Algorithm (RGA), Ant Colony Opti- } \\
\text { mization Algorithm in Hypercube Framework } \\
\text { (HC-ACO), and Harmony Search Algorithm } \\
\text { (HSA). }\end{array}$ & $\begin{array}{l}\text { Does not consider network reliability as } \\
\text { objective. }\end{array}$ \\
\hline
\end{tabular}




\begin{tabular}{|c|c|c|}
\hline References & Advantages & Disadvantages \\
\hline$[51]$ & $\begin{array}{l}\text { Perform reconfiguration as well as allocation } \\
\text { of DGs in the network. } \\
\text { Consider load variations (light, nominal and } \\
\text { heavy). Test the approach on } 69 \text {-bus networks. }\end{array}$ & $\begin{array}{l}\text { Does not consider network reliability as } \\
\text { objective. }\end{array}$ \\
\hline$[15]$ & $\begin{array}{l}\text { Used an improved GA that converges to the } \\
\text { local optimal quickly. } \\
\text { Improves crossover operation to avoid looping } \\
\text { in the distribution system. } \\
\text { Considers reliability assessment methods. } \\
\text { EGA results are better than GA. }\end{array}$ & $\begin{array}{l}\text { Does not consider load uncertainties. } \\
\text { Does not consider DG mechanisms. }\end{array}$ \\
\hline$[41]$ & Uses charge flow method. & $\begin{array}{l}\text { Does not consider DG mechanisms. } \\
\text { Does not consider network reliability as } \\
\text { objective. }\end{array}$ \\
\hline$[17]$ & $\begin{array}{l}\text { Uses TFN (Triangular Fuzzy Number) to rep- } \\
\text { resent load model. } \\
\text { Uses Pareto solutions and fuzzy methodology } \\
\text { in the decision process. } \\
\text { Considers DG mechanisms allocations. } \\
\text { Tested method with and without balanced } \\
\text { loads Optimal Pareto solutions are compared } \\
\text { with NSGA-II, MOPSO and MOABC and } \\
\text { show better results. }\end{array}$ & $\begin{array}{l}\text { Does not consider network reliability as } \\
\text { objective. }\end{array}$ \\
\hline [53] & $\begin{array}{l}\text { Scale and locate DGs. } \\
\text { Use the weigh method to find the optimal } \\
\text { solution. } \\
\text { The graph theory that allows you to determine } \\
\text { search space helps Cuckoo Search } \\
\text { Algorithm reduce a set of improper network } \\
\text { configurations in each state of the optimiza- } \\
\text { tion process. } \\
\text { The results proved that Adaptive Cuckoo } \\
\text { Search Algorithm (ACSA) is better than FWA } \\
\text { and HSA in most scenarios. }\end{array}$ & $\begin{array}{l}\text { Does not consider network reliability as } \\
\text { objective. } \\
\text { Does not consider load uncertainties. }\end{array}$ \\
\hline$[24]$ & $\begin{array}{l}\text { Uses two types of objectives, which differ in } \\
\text { their normalization. } \\
\text { Uses Pareto solutions. }\end{array}$ & $\begin{array}{l}\text { Does not consider DG mechanisms. } \\
\text { Does not consider load uncertainties. }\end{array}$ \\
\hline$[26]$ & $\begin{array}{l}\text { Considers reconfiguration with integration of } \\
\text { DGs at the same time. } \\
\text { By introducing a heuristic rule, they can } \\
\text { improve BE. } \\
\text { Test the approach on } 69 \text {-bus networks. }\end{array}$ & $\begin{array}{l}\text { Does not consider network reliability as } \\
\text { objective. } \\
\text { Does not consider load uncertainty. }\end{array}$ \\
\hline$[88]$ & $\begin{array}{l}\text { Considers an unbalanced three-phase distribu- } \\
\text { tion network. } \\
\text { Dynamic method takes into account the same } \\
\text { things as the static one. } \\
\text { Does not consider introducing DGs into the } \\
\text { network. }\end{array}$ & $\begin{array}{l}\text { Do not consider network reliability as objec- } \\
\text { tive. } \\
\text { Do not refer to device sizing. }\end{array}$ \\
\hline
\end{tabular}




\begin{tabular}{|c|c|c|}
\hline References & Advantages & Disadvantages \\
\hline$[5]$ & $\begin{array}{l}\text { Ensures the radial configuration of the net- } \\
\text { work only with the chosen method, without } \\
\text { having to use restriction for this point. } \\
\text { Final solution is independent of the initial net- } \\
\text { work, due to the use of a constructive } \\
\text { methodology. } \\
\text { Method confirmed through successful imple- } \\
\text { mentation in different types of networks. }\end{array}$ & $\begin{array}{l}\text { Does not consider network reliability as } \\
\text { objective. } \\
\text { Does not consider DG mechanisms. }\end{array}$ \\
\hline$[37]$ & $\begin{array}{l}\text { Reconfiguration is determined at the same } \\
\text { time as the optimal location and sizing of DGs. } \\
\text { Multi-objective analysis is performed using } \\
\text { Pareto solutions and final solution is deter- } \\
\text { mined using a fuzzy satisfaction criterion. }\end{array}$ & $\begin{array}{l}\text { Do not consider network reliability as } \\
\text { objective. }\end{array}$ \\
\hline$[81]$ & $\begin{array}{l}\text { Algorithm performs optimal localization and } \\
\text { scaling for DG devices as well as network } \\
\text { reconfiguration. } \\
\text { Test the approach on } 69 \text {-bus networks as sat- } \\
\text { isfactory results. }\end{array}$ & $\begin{array}{l}\text { Does not consider network reliability as } \\
\text { objective. } \\
\text { Does not consider load uncertainty. }\end{array}$ \\
\hline [65] & $\begin{array}{l}\text { Use DG in the network and determine their } \\
\text { optimal location and sizing. } \\
\text { Also consider different types of DG devices } \\
(1,2,3 \text { and } 4) \text {. }\end{array}$ & $\begin{array}{l}\text { Does not consider network reliability as } \\
\text { objective. } \\
\text { Do not perform reconfiguration or have any } \\
\text { algorithm for this effect. } \\
\text { Do not consider load uncertainties. }\end{array}$ \\
\hline [79] & $\begin{array}{l}\text { Combine DSTATCOM and DG allocation. } \\
\text { Present a multi-objective function where, to } \\
\text { calculate the solution, the weights method is } \\
\text { implemented, in order to prioritize the impact } \\
\text { of the considered indexes. } \\
\text { Consider variations in load (Light, normal and } \\
\text { peak load). }\end{array}$ & $\begin{array}{l}\text { Do not perform reconfiguration or have any } \\
\text { algorithm for this effect. }\end{array}$ \\
\hline$[31]$ & $\begin{array}{l}\text { Incorporate SOP to increase DG hosting } \\
\text { capacity on the network. }\end{array}$ & $\begin{array}{l}\text { Do not consider reliability as objective. } \\
\text { Do not consider network reconfiguration } \\
\text { with device combination. } \\
\text { Does not consider load uncertainties. }\end{array}$ \\
\hline$[29]$ & $\begin{array}{l}\text { Incorporate SOP to increase DG hosting } \\
\text { capacity on the network. }\end{array}$ & $\begin{array}{l}\text { Does not consider reliability as objective. } \\
\text { Does not consider network reconfiguration } \\
\text { with device combination. }\end{array}$ \\
\hline$[20]$ & $\begin{array}{l}\text { Use the method for reconfiguration and instal- } \\
\text { lation of DG and DSTATCOM unit. } \\
\text { Use Pareto solutions to deal with the multi- } \\
\text { objective approach. } \\
\text { Test the approach on } 69 \text {-bus and 118-bus net- } \\
\text { works. }\end{array}$ & Do not consider load uncertainties. \\
\hline
\end{tabular}




\begin{tabular}{|c|c|c|}
\hline References & Advantages & Disadvantages \\
\hline$[33]$ & $\begin{array}{l}\text { Take into account energy losses as well as } \\
\text { the improvement of the voltage profile, this } \\
\text { through a penalty factor for the latter. } \\
\text { Use TLBO for both reconfiguration and DG } \\
\text { integration. } \\
\text { Considers load variation. }\end{array}$ & Do not consider device sizing. \\
\hline$[6]$ & $\begin{array}{l}\text { Consider location and sizing DGs. } \\
\text { Compares results with other methods such } \\
\text { as FWA, HSA, GA, RGA and the results } \\
\text { obtained were better, along with the compu- } \\
\text { tational time. }\end{array}$ & $\begin{array}{l}\text { Does not consider network reliability as } \\
\text { objective. } \\
\text { Does not consider load uncertainties. }\end{array}$ \\
\hline [9] & Considers SOP reconfiguration and allocation. & Do not consider load uncertainties. \\
\hline [60] & $\begin{array}{l}\text { Introduce DSTATCOM. } \\
\text { Allocate the device through PLI and VSI for } \\
\text { result comparison. }\end{array}$ & $\begin{array}{l}\text { Do not consider load uncertainties. } \\
\text { Do not perform reconfiguration or have any } \\
\text { algorithm for this effect. }\end{array}$ \\
\hline$[83]$ & $\begin{array}{l}\text { Consider two different types of DGs ( } 1 \text { and } 3) \\
\text { and determine their optimal location. }\end{array}$ & $\begin{array}{l}\text { Does not consider network reliability as } \\
\text { objective. } \\
\text { Do not perform reconfiguration or have any } \\
\text { algorithm for this effect. } \\
\text { Do not consider load uncertainties. }\end{array}$ \\
\hline [28] & $\begin{array}{l}\text { LSF reduces search space which results in } \\
\text { shorter optimization process times. } \\
\text { Introduce the combination of DGs with } \\
\text { DSTATCOM. }\end{array}$ & Do not consider load uncertainties. \\
\hline$[58]$ & $\begin{array}{l}\text { Introduce SOP to increase the penetration of } \\
\text { DGs in the network. }\end{array}$ & $\begin{array}{l}\text { Does not consider network reliability as } \\
\text { objective. } \\
\text { Does not consider load uncertainty. }\end{array}$ \\
\hline$[30]$ & $\begin{array}{l}\text { Use the weight method to handle the two } \\
\text { required objective functions. } \\
\text { Incorporate SOP and DG into the network. }\end{array}$ & Do not consider reliability as objective. \\
\hline [84] & $\begin{array}{l}\text { Use Soft Open Points integrated in the net- } \\
\text { work. } \\
\text { Through convex relaxation and lineariza- } \\
\text { tion applied to the initial problem, MISOCP } \\
\text { presents good convergence. }\end{array}$ & $\begin{array}{l}\text { Does not consider network reliability as } \\
\text { objective. } \\
\text { Does not consider load uncertainty. }\end{array}$ \\
\hline$[45]$ & $\begin{array}{l}\text { Incorporate SOP and DG into the network to } \\
\text { increase DG penetration. } \\
\text { Generation and three-phase balanced load } \\
\text { were considered. }\end{array}$ & $\begin{array}{l}\text { Do not consider network reconfiguration } \\
\text { with device combination. }\end{array}$ \\
\hline [4] & $\begin{array}{l}\text { Create a fuzzy strategy to handle all objec- } \\
\text { tive functions, normalizing them to a range } \\
\text { between } 0 \text { and } 1 . \\
\text { Use Pareto solutions. } \\
\text { Consider DG mechanisms. }\end{array}$ & Do not consider load uncertainties. \\
\hline
\end{tabular}




\begin{tabular}{|c|c|c|}
\hline References & Advantages & Disadvantages \\
\hline$[49]$ & $\begin{array}{l}\text { Considers reconfiguration along with the loca- } \\
\text { tion and sizing of DSTATCOM. } \\
\text { Test the approach on 29-bus networks. }\end{array}$ & $\begin{array}{l}\text { Do not consider network reliability as objec- } \\
\text { tive. } \\
\text { Do not consider load uncertainties. }\end{array}$ \\
\hline$[35]$ & $\begin{array}{l}\text { Apply method for simultaneous reconfigura- } \\
\text { tion, redesign and allocation of DG devices. } \\
\text { Present a multi-objective function employing } \\
\text { the weights method, according to the impor- } \\
\text { tance given to each objective. }\end{array}$ & Do not consider load uncertainties. \\
\hline$[76]$ & $\begin{array}{l}\text { Scalable method. } \\
\text { Break down the problem into subproblems, } \\
\text { always employing the radiality condition, and } \\
\text { solve them with second-order conical } \\
\text { programming. } \\
\text { Aggregate the combinations of solved sub- } \\
\text { problems using a zero-suppressed binary deci- } \\
\text { sion diagram vector (ZDDV). } \\
\text { Test results on } 432 \text {-bus networks. } \\
\text { Integrate DGs into the network. }\end{array}$ & $\begin{array}{l}\text { Does not consider network reliability as } \\
\text { objective. } \\
\text { Do not consider load uncertainties. }\end{array}$ \\
\hline$[39]$ & $\begin{array}{l}\text { Introduces the scalable concept. } \\
\text { Breaks down the initial problem into indepen- } \\
\text { dent subproblems and solves them, allowing } \\
\text { for the large-scale problem to be solved in } \\
\text { parts, costing the system less complexity. }\end{array}$ & Do not consider load uncertainties. \\
\hline$[48]$ & $\begin{array}{l}\text { Models DGs as PQ or PV nodes. } \\
\text { Uses an unbalance three phase power flow } \\
\text { algorithm. }\end{array}$ & $\begin{array}{l}\text { Do not consider network reconfiguration } \\
\text { with device combination. }\end{array}$ \\
\hline$[22]$ & $\begin{array}{l}\text { Test balanced and unbalanced systems. } \\
\text { Can be applied to systems of various sizes. } \\
\text { Compares with other methods like Fuzzy- } \\
\text { ACO, B\&B, HAS, BPSO and although the } \\
\text { reduction percentage is not the best, it has } \\
\text { the best computational time. } \\
\text { New coding helps prevent disconnected } \\
\text { branches and creating closed loops on the } \\
\text { network. } \\
\text { Using modified heuristics helps reduce compu- } \\
\text { tational time significantly. } \\
\text { Final solution is independent of the state of } \\
\text { the switches in the initial network } \\
\text { configuration. }\end{array}$ & $\begin{array}{l}\text { Only consider costs. } \\
\text { Does not consider network reliability as } \\
\text { objective. }\end{array}$ \\
\hline$[43]$ & $\begin{array}{l}\text { Final solution obtained does not depend on } \\
\text { initial network configuration. } \\
\text { Uses Pareto solutions. } \\
\text { Max-min method is implemented to determine } \\
\text { the best solution. }\end{array}$ & $\begin{array}{l}\text { Does not consider network reliability as } \\
\text { objective. } \\
\text { Does not consider load uncertainties. } \\
\text { Does not consider DG mechanisms. }\end{array}$ \\
\hline
\end{tabular}




\begin{tabular}{|c|c|c|}
\hline References & Advantages & Disadvantages \\
\hline$[67]$ & $\begin{array}{l}\text { Consider allocating DG mechanisms. } \\
\text { Consider adding another node with a branch } \\
\text { to connect DG to the network. } \\
\text { Consider load variation through daily curves. }\end{array}$ & $\begin{array}{l}\text { Does not consider network reliability as } \\
\text { objective. }\end{array}$ \\
\hline [13] & $\begin{array}{l}\text { Considers the uncertainty of the loads, i.e. } \\
\text { considers problems associated with the actual } \\
\text { distributions. } \\
\text { The quality of the method solution has been } \\
\text { proven by comparing it with Exhaustive } \\
\text { Search and other considered papers. } \\
\text { Considers load variation over the planning } \\
\text { horizon of the operation and represents it } \\
\text { using typical daily load curves. } \\
\text { Method that prevents the solution from falling } \\
\text { into points considered local optima. }\end{array}$ & $\begin{array}{l}\text { Does not consider network reliability as } \\
\text { objective. } \\
\text { Does not consider DG mechanisms. }\end{array}$ \\
\hline$[21]$ & $\begin{array}{l}\text { Add to the heuristic a mutation process, to } \\
\text { avoid local optimal and explore new areas of } \\
\text { research space. } \\
\text { Considers the network unbalanced. }\end{array}$ & Do not consider device integration. \\
\hline$[36]$ & $\begin{array}{l}\text { Considers the introduction of harmonic filters } \\
\text { as well as DGs in the network. } \\
\text { Use two GA cores to initially obtain reconfig- } \\
\text { uration results and then the harmonic filter } \\
\text { allocation results. } \\
\text { The backward/forward sweep method is } \\
\text { implemented to solve the harmonic charge } \\
\text { flow. } \\
\text { Use high penetration of non-linear loads. }\end{array}$ & $\begin{array}{l}\text { Do not consider network reliability as their } \\
\text { objective. }\end{array}$ \\
\hline$[12]$ & $\begin{array}{l}\text { Development of a decoder using graph theory } \\
\text { to generate only viable solutions. }\end{array}$ & $\begin{array}{l}\text { Do not consider network reliability as } \\
\text { objective. } \\
\text { Do not consider device integration, i.e. DG. } \\
\text { Does not consider load uncertainty. }\end{array}$ \\
\hline$[7]$ & $\begin{array}{l}\text { Integration of GA process operators to ensure } \\
\text { exchange and survival of the best genetic } \\
\text { material. } \\
\text { Tests results for } 70,136 \text {, and } 880 \text {-bus } \\
\text { networks. } \\
\text { Applied cycle-break algorithms demonstrate } \\
\text { greater efficiency compared to greedy } \\
\text { algorithms. }\end{array}$ & Do not introduce devices to improve results. \\
\hline$[62]$ & $\begin{array}{l}\text { The proposed algorithm is very efficient in } \\
\text { finding global optimums and is able to obtain } \\
\text { a Pareto solution containing better results } \\
\text { than other methods. }\end{array}$ & $\begin{array}{l}\text { Does not consider network reliability as } \\
\text { objective. } \\
\text { Does not consider load uncertainties. } \\
\text { Does not consider DG mechanisms. }\end{array}$ \\
\hline
\end{tabular}




\begin{tabular}{|c|c|c|}
\hline References & Advantages & Disadvantages \\
\hline$[86]$ & $\begin{array}{l}\text { Introduce DSTATCOM and find optimal loca- } \\
\text { tion and sizing through HSA. }\end{array}$ & $\begin{array}{l}\text { Does not consider network reliability as } \\
\text { objective. } \\
\text { Do not perform reconfiguration or have any } \\
\text { algorithm for this effect. }\end{array}$ \\
\hline$[40]$ & $\begin{array}{l}\text { Considers charge variation (industrial, resi- } \\
\text { dential, commercial) }\end{array}$ & $\begin{array}{l}\text { Considers several objective functions yet } \\
\text { does not consider them simultaneously. } \\
\text { Does not consider device integration. }\end{array}$ \\
\hline$[38]$ & $\begin{array}{l}\text { Method performs reconfiguration, DG sizing, } \\
\text { and simultaneous tap changer tuning. } \\
\text { Consider load variation (Light, Heavy and } \\
\text { Nominal). }\end{array}$ & $\begin{array}{l}\text { Does not consider network reliability as } \\
\text { objective. }\end{array}$ \\
\hline$[68]$ & $\begin{array}{l}\text { Adds to MVMO a special mapping function } \\
\text { for mutation operation which allows a con- } \\
\text { trolled change of stages where the exploration } \\
\text { process is the priority. }\end{array}$ & $\begin{array}{l}\text { Do not consider device integration. } \\
\text { Do not consider network reliability as objec- } \\
\text { tive. } \\
\text { Do not consider load uncertainties. }\end{array}$ \\
\hline$[3]$ & $\begin{array}{l}\text { Considers the variable nature of the load pro- } \\
\text { file for different energy sectors. } \\
\text { The behavior of responsive loads is considered } \\
\text { through modeling in DR (Response Demand) } \\
\text { programs. } \\
\text { Uses a bevel analysis, using PSO on the first } \\
\text { and sensitivity analysis on the second. }\end{array}$ & Does not consider DG mechanisms. \\
\hline$[42]$ & $\begin{array}{l}\text { Use the weights method to find the optimal } \\
\text { solution. } \\
\text { The adaptation allows the algorithm to over- } \\
\text { come the prematurity problems of solutions } \\
\text { that PSO reveals. }\end{array}$ & $\begin{array}{l}\text { Does not consider network reliability as } \\
\text { objective. } \\
\text { Does not consider load uncertainties. } \\
\text { Does not consider DG mechanisms. }\end{array}$ \\
\hline$[56]$ & $\begin{array}{l}\text { Improved BPSO, allowing for greater popula- } \\
\text { tion convergence and a reduction in the num- } \\
\text { ber of iterations for the optimal solution. } \\
\text { Additionally, the method also allows for a bet- } \\
\text { ter exploration of the search space. }\end{array}$ & $\begin{array}{l}\text { Do not consider network reliability as objec- } \\
\text { tive. } \\
\text { Do not consider device integration. } \\
\text { Do not consider load uncertainties. }\end{array}$ \\
\hline$[73]$ & $\begin{array}{l}\text { Method is used for reconfiguring, locating and } \\
\text { scaling DGs simultaneously. }\end{array}$ & $\begin{array}{l}\text { Does not consider network reliability as } \\
\text { objective. } \\
\text { Does not consider load uncertainty. }\end{array}$ \\
\hline$[66]$ & $\begin{array}{l}\text { Considers a multi-objective approach, where } \\
\text { Pareto solutions are applied. } \\
\text { Incorporate TOPSIS method that deals with } \\
\text { the various Pareto solutions for the final } \\
\text { decision. } \\
\text { Considers concurrent DSTATCOM reconfigu- } \\
\text { ration and allocation. } \\
\text { Test the approach on } 69 \text {-bus networks. }\end{array}$ & Do not consider load uncertainties. \\
\hline
\end{tabular}




\begin{tabular}{|c|c|c|}
\hline References & Advantages & Disadvantages \\
\hline$[25]$ & $\begin{array}{l}\text { AGWO aims to improve the exploration and } \\
\text { exploration process of the GWO. }\end{array}$ & $\begin{array}{l}\text { Does not consider network reliability as } \\
\text { objective. } \\
\text { Does not consider load uncertainty. } \\
\text { Does not include devices for improved } \\
\text { results. }\end{array}$ \\
\hline$[52]$ & $\begin{array}{l}\text { Test the approach on } 69 \text {-bus networks as sat- } \\
\text { isfactory results. } \\
\text { Considers two objectives integrated into one } \\
\text { objective. } \\
\text { Uses weight method. }\end{array}$ & $\begin{array}{l}\text { Does not device integration. } \\
\text { Does not consider load uncertainty. }\end{array}$ \\
\hline [64] & $\begin{array}{l}\text { Test the approach on } 69 \text {-bus networks as sat- } \\
\text { isfactory results. }\end{array}$ & $\begin{array}{l}\text { Does not consider device integration. } \\
\text { Does not consider network reliability as } \\
\text { objective. } \\
\text { Does not consider load variations. }\end{array}$ \\
\hline [63] & $\begin{array}{l}\text { Considers different types of DGs. } \\
\text { Takes into account sizing of the DGs. } \\
\text { Uses an Index Vector method to find device } \\
\text { locations to minimize search space. }\end{array}$ & $\begin{array}{l}\text { Does not consider network reliability as } \\
\text { objective. } \\
\text { Does not consider load uncertainty. }\end{array}$ \\
\hline$[1]$ & $\begin{array}{l}\text { Uses capacitor banks for reactive power } \\
\text { control. } \\
\text { Considers location and sizing of devices. }\end{array}$ & $\begin{array}{l}\text { Does not consider network reliability as } \\
\text { objective. } \\
\text { Does not consider load uncertainty. } \\
\text { Does not perform network reconfiguration } \\
\text { with FPA algorithm. }\end{array}$ \\
\hline$[2]$ & $\begin{array}{l}\text { Use the method for locating and allocating } \\
\text { capacitor banks. } \\
\text { Test the approach on 69-bus networks. }\end{array}$ & $\begin{array}{l}\text { Do not consider network reliability as objec- } \\
\text { tive. } \\
\text { Do not consider load uncertainties. } \\
\text { Do not consider network reconfiguration } \\
\text { with device combination. }\end{array}$ \\
\hline$[54]$ & $\begin{array}{l}\text { To find the final solution use the max-min } \\
\text { method. } \\
\text { Achieves faster convergence compared to CGA } \\
\text { and CSA. }\end{array}$ & $\begin{array}{l}\text { Does not consider network reliability as } \\
\text { objective. } \\
\text { Does not consider load uncertainties. } \\
\text { Does not consider DG mechanisms. }\end{array}$ \\
\hline [59] & $\begin{array}{l}\text { Considers DGs and takes into account their } \\
\text { level of penetration. } \\
\text { Uses Pareto solutions. } \\
\text { Uses SOP. }\end{array}$ & $\begin{array}{l}\text { Does not consider network reliability as } \\
\text { objective. } \\
\text { Does not consider load uncertainties. }\end{array}$ \\
\hline$[78]$ & $\begin{array}{l}\text { Proposes basic modifications to the GSO } \\
\text { (Group Search Algorithm) algorithm in order } \\
\text { to change it to a binary search tool. } \\
\text { Applicable to other larger networks. }\end{array}$ & $\begin{array}{l}\text { Does not consider network reliability as } \\
\text { objective. } \\
\text { Does not consider DG mechanisms. }\end{array}$ \\
\hline
\end{tabular}




\begin{tabular}{|c|c|c|}
\hline References & Advantages & Disadvantages \\
\hline$[27]$ & $\begin{array}{l}\text { Analyze results for the case where a series fail- } \\
\text { ure is considered in a node, for the case where } \\
\text { a series failure is considered in a line, and for } \\
\text { both cases simultaneously - by isolating each } \\
\text { element where the failure occurs. } \\
\text { Method tested in medium and high radial } \\
\text { scale systems and results proved superior to } \\
\text { methods such as GA, RGA, ITS and HSA. }\end{array}$ & $\begin{array}{l}\text { Does not consider load uncertainty. } \\
\text { Does not insert DG mechanisms. } \\
\text { Does not consider network reliability as } \\
\text { objective. }\end{array}$ \\
\hline$[14]$ & $\begin{array}{l}\text { Allocate DGs along with DSTATCOM. } \\
\text { Consider different load factors (residential, } \\
\text { commercial and industrial). } \\
\text { Takes into account system reliability on pur- } \\
\text { pose. }\end{array}$ & Does not consider load uncertainty. \\
\hline$[87]$ & $\begin{array}{l}\text { Consider Load Variations. } \\
\text { Introduce DSTATCOM allocation. } \\
\text { A curve fitting technique is used to find the } \\
\text { optimal DSTATCOM size at each load level. } \\
\text { Test the approach on } 69 \text {-bus networks. }\end{array}$ & $\begin{array}{l}\text { Does not consider network reliability as } \\
\text { objective. } \\
\text { Do not perform reconfiguration or have any } \\
\text { algorithm for this effect. }\end{array}$ \\
\hline$[55]$ & $\begin{array}{l}\text { Add the adaptive technique to improve } \\
\text { SFLA's generation and research process. } \\
\text { Graph theory is used to avoid mixing and iso- } \\
\text { lation of node conditions. } \\
\text { Use the method for reconfiguration and device } \\
\text { allocation DG. } \\
\text { Consider two goals that merge into one goal. } \\
\text { Use the weigh method. } \\
\text { Test the approach on } 69 \text {-bus network. }\end{array}$ & Do not consider load uncertainties. \\
\hline$[80]$ & $\begin{array}{l}\text { Present an approach capable of performing } \\
\text { reconfiguration, as well as allocation of mul- } \\
\text { tiple DGs in the network. } \\
\text { Create a fuzzy environment for calculating } \\
\text { multi-objective system by placing variables in } \\
\text { a range of values ??between } 0 \text { and } 1 . \\
\text { Consider different types of DGs to understand } \\
\text { which are the best results. }\end{array}$ & Do not consider load uncertainties. \\
\hline$[72]$ & $\begin{array}{l}\text { Considers variable search. } \\
\text { The results of the algorithm are compared } \\
\text { with references that consider a fixed or vari- } \\
\text { able search and in all cases Copt-aiNet reveals } \\
\text { the best results. }\end{array}$ & $\begin{array}{l}\text { Does not consider network reliability as } \\
\text { objective. } \\
\text { Does not consider DG mechanisms. }\end{array}$ \\
\hline
\end{tabular}




\begin{tabular}{|c|c|c|}
\hline References & Advantages & Disadvantages \\
\hline$[71]$ & $\begin{array}{l}\text { Implement a coding for the distribution sys- } \\
\text { tem reconfiguration problem that guarantees } \\
\text { excellent performance in the characterization } \\
\text { of a smaller research space, formed only by } \\
\text { radial topologies. }\end{array}$ & $\begin{array}{l}\text { Does not consider network reliability as } \\
\text { objective. } \\
\text { Does not consider load uncertainty. } \\
\text { Do not use any devices to improve results, } \\
\text { such as DGs. }\end{array}$ \\
\hline$[75]$ & $\begin{array}{l}\text { Determine optimal location and sizing of } \\
\text { DSTATCOM through IA. } \\
\text { Test the approach on 69-bus networks. }\end{array}$ & $\begin{array}{l}\text { Do not consider load uncertainties. } \\
\text { Do not perform reconfiguration or have any } \\
\text { algorithm for this effect }\end{array}$ \\
\hline$[46]$ & $\begin{array}{l}\text { Considers DG devices in its network. } \\
\text { Takes system reliability into account as a goal. } \\
\text { Proposed method does not need to regulate } \\
\text { any parameters except population size and } \\
\text { convergence criterion. }\end{array}$ & $\begin{array}{l}\text { Does not consider load uncertainty. } \\
\text { Does not take into account device sizing. }\end{array}$ \\
\hline$[34]$ & $\begin{array}{l}\text { The diversity of load available to different } \\
\text { types of consumers as well as the effect of sea- } \\
\text { sonal variations are taken into account. } \\
\text { The introduction of two learning processes } \\
\text { into the standard TLBO, has allowed for } \\
\text { increased convergence, accuracy and effi- } \\
\text { ciency. }\end{array}$ & $\begin{array}{l}\text { Does not consider any type of device on the } \\
\text { network for improved results. }\end{array}$ \\
\hline [69] & $\begin{array}{l}\text { Consider both balanced and unbalanced sys- } \\
\text { tems. } \\
\text { Considers a fuzzy strategy for grouping all } \\
\text { objective functions into one function. }\end{array}$ & Does not consider load uncertainty. \\
\hline [4] & $\begin{array}{l}\text { Consider the penetration level of RES (renew- } \\
\text { able energy sources)/DGs. } \\
\text { Consider a short-circuit voltage stability } \\
\text { index. } \\
\text { The proposed algorithm adapts to both mono } \\
\text { and multi-objective problems. } \\
\text { Uses Pareto solutions. } \\
\text { Stable performance for both small- and large- } \\
\text { scale systems. }\end{array}$ & $\begin{array}{l}\text { Does not consider network reliability as } \\
\text { objective. } \\
\text { Does not consider load uncertainties. }\end{array}$ \\
\hline$[18]$ & $\begin{array}{l}\text { Uses clustering in the approach. } \\
\text { Has better computational time than the } \\
\text { Switching Algorithm. }\end{array}$ & $\begin{array}{l}\text { Does not consider load uncertainties. } \\
\text { Does not consider DG mechanisms. } \\
\text { Does not consider network reliability as } \\
\text { objective. }\end{array}$ \\
\hline$[50]$ & $\begin{array}{l}\text { Hybrid method that joins RBFN (Radial } \\
\text { Basis Function Network) based on ANN (Arti- } \\
\text { ficial Neural Network) with CART (Classifica- } \\
\text { tion and Regression Trees), and the learning } \\
\text { of data with Monte Carlo simulation is also } \\
\text { introduced. } \\
\text { More efficient than TS. }\end{array}$ & $\begin{array}{l}\text { Does not consider DG mechanisms. } \\
\text { Does not consider network reliability as } \\
\text { objective. }\end{array}$ \\
\hline
\end{tabular}




\begin{tabular}{|c|c|c|}
\hline References & Advantages & Disadvantages \\
\hline$[47]$ & $\begin{array}{l}\text { In addition to reconfiguration, DGs are intro- } \\
\text { duced and the type of device to implement } \\
\text { with the best results }(1,2,3 \text { or } 4) \text { is studied. }\end{array}$ & $\begin{array}{l}\text { Do not consider network reliability as } \\
\text { objective. } \\
\text { Do not consider load uncertainties. }\end{array}$ \\
\hline$[19]$ & $\begin{array}{l}\text { Includes tests on } 69 \text {-bus and 119-bus networks } \\
\text { with satisfactory results. }\end{array}$ & $\begin{array}{l}\text { Does not consider load uncertainty. } \\
\text { Do not consider device integration. }\end{array}$ \\
\hline [82] & $\begin{array}{l}\text { Apply a coding scheme based on graph theory } \\
\text { to maintain radial network configuration. }\end{array}$ & $\begin{array}{l}\text { Do not consider device integration. } \\
\text { Do not consider network reliability as } \\
\text { objective. } \\
\text { Do not consider load uncertainties. }\end{array}$ \\
\hline$[57]$ & $\begin{array}{l}\text { Use the multi-criteria method for decision } \\
\text { making - Analytic Hierarchic Process (AHP). } \\
\text { Methodology for parsing feeder parallelism } \\
\text { using the Euler Discretization method - } \\
\text { ensures that switching reconfiguration does } \\
\text { not violate constraints. } \\
\text { Computer-integrated analysis with supervi- } \\
\text { sory control and remote control data acquisi- } \\
\text { tion of switches allowing automatic real-time } \\
\text { reconfiguration. }\end{array}$ & \\
\hline
\end{tabular}

\section{REFERENCES}

[1] A.Y. Abdelaziz, E.S. Ali and S.M. Abd Elazim, Optimal sizing and locations of capacitors in radial distribution systems via flower pollination optimization algorithm and power loss index. Eng. Sci. Technol. Int. J. 19 (2016) 610-618.

[2] A.Y. Abdelaziz, E.S. Ali and S.M. Abd Elazim, Flower pollination algorithm and loss sensitivity factors for optimal sizing and placement of capacitors in radial distribution systems. Electr. Power Energy Syst. 78 (2016) 207-214.

[3] H. Arasteh, M.S. Sepasian and V. Vahidinasab, An aggregated model for coordinated planning and reconfiguration of electric distribution networks. Energy 94 (2016) $786 \mathrm{e} 798$.

[4] A. Azizivahed, H. Narimani, E. Naderi, M. Fathi and M.R. Narimani, A hybrid evolutionary algorithm for secure multi-objective distribution feeder reconfiguration. Energy 138 (2017) 355-373.

[5] A. Bayat, Uniform voltage distribution based constructive algorithm for optimal reconfiguration of electric distribution networks. Electr. Power Syst. Res. 104 (2013) 146-155.

[6] A. Bayat, A. Bagheri and R. Noroozian, Optimal siting and sizing of distributed generation accompanied by reconfiguration of distribution networks for maximum loss reduction by using a new UVDA-based heuristic method. Electr. Power Energy Syst. 77 (2016) 360-371.

[7] R. Čadenović, D. Jakus, P. Sarajčev and J. Vasilj, Optimal distribution network reconfiguration through integration of cyclebreak and genetic algorithms. Energies 11 (2018) 1278.

[8] W. Cao, J. Wu, N. Jenkins, C. Wang and T. Green, Operating principle of Soft Open Points for electrical distribution network operation. Appl. Energy 164 (2016) 245-257.

[9] W. Cao, J. Wu, N. Jenkins, C. Wang and T. Green, Benefits analysis of Soft Open Points for electrical distribution network operation. Appl. Energy 165 (2016) 36-47.

[10] M. Cavlovic, Challenges of optimizing the integration of distributed generation into the distribution network. In: 2011 8th International Conference on the European Energy Market (EEM). IEEE (2011) 419-426.

[11] G. Chicco and A. Mazza, Assessment of optimal distribution network reconfiguration results using stochastic dominance concepts. Sustainable Energy Netw. Netw. 9 (2017) 75-79.

[12] H. de Faria, M.G.C. Resende and D. Ernst, A biased random key genetic algorithm applied to the electric distribution network reconfiguration problem. J. Heuristics 23 (2017) 533-550.

[13] E.J. de Oliveira, G.J. Rosseti, L.W. de Oliveira, F.V. Gomes and W. Peres, New algorithm for reconfiguration and operating procedures in electric distribution systems. Electr. Power Energy Syst. 57 (2014) 129-134.

[14] K.R. Devabalaji and K. Ravi, Optimal size and siting of multiple DG and DSTATCOM in radial distribution system using bacterial foraging optimization algorithm. Ain Shams Eng. J. 7 (2016) 959-971.

[15] D.-L. Duan, X.-D. Ling, X.-Y. Wu and B. Zhong, Reconfiguration of distribution network for loss reduction and reliability improvement based on an enhanced genetic algorithm. Int J. Electr. Power Energy Syst. 64 (2015) 88-89. 
[16] A. Escalera, B. Hayes and M. Prodanović, A survey of reliability assessment techniques for modern distribution networks. Renew. Sustainable Energy Rev. 91 (2018) 344-357.

[17] M. Esmaeili, M. Sedighizadeh and M. Esmaili, Multi-objective optimal reconfiguration and DG (Distributed Generation) power allocation in distribution networks using Big Bang-Big Crunch algorithm considering load uncertainty. Energy 103 (2016) $86 \mathrm{e} 99$.

[18] H. Fathabadi, Power distribution network reconfiguration for power loss minimization using novel dynamic fuzzy c-means (dFCM) clustering based ANN approach. Electr. Power Energy Syst. 78 (2016) 96-107.

[19] A. Fathy, M. El-Arini and O. El-Baksawy, An efficient methodology for optimal reconfiguration of electric distribution network considering reliability indices via binary particle swarm gravity search algorithm. Neural Comput. Appl. 30 (2017) $2843-2858$.

[20] S. Ganesh and R. Kanimozhi, Meta-heuristic technique for network reconfiguration in distribution system with photovoltaic and D-STATCOM. IET Gener. Transm. Distrib. 12 (2018) 4524-4535.

[21] S. Ghasemi, Balanced and unbalanced distribution networks reconfiguration considering reliability indices. Ain Shams Eng. J. 9 (2018) 1567-1579.

[22] S. Ghasemi and J. Moshtagh, A novel codification and modified heuristic approaches for optimal reconfiguration of distribution networks considering losses cost and cost benefit from voltage profile improvement. Appl. Soft Comput. 25 (2014) $360-368$.

[23] F. Glover and G.A. Kochenberger, Handbook of Metaheuristics. Kluwer Academic Publihers (2003).

[24] N. Gupta, A. Swarnkar and K.R. Niazi, Distribution network reconfiguration for power quality and reliability improvement using Genetic Algorithms. Electr. Power Energy Syst. 54 (2014) 664-671.

[25] H. Hamour, S. Kamel, L. Nasrat and J. Yu, Distribution network reconfiguration using augmented grey wolf optimization algorithm for power loss minimization. In: International Conference on Innovative Trends in Computer Engineering (ITCE2019), Aswan, Egypt, 2-4 February. IEEE (2019).

[26] Q. Hao, Z. Gao, X. Bai and M. Cao, Two-level reconfiguration algorithm of branch exchange and variable neighborhood search for active distribution network. Syst. Sci. Control Eng.: Open Access J. 6 (2018) 109-117.

[27] A.M. Imran and M. Kowsalya, A new power system reconfiguration scheme for power loss minimization and voltage profile enhancement using fireworks algorithm. Electr. Power Energy Syst. 62 (2014) 312-322.

[28] F. Iqbal, M. Tauseef Khan and A. Shahzad Siddiqui, Optimal placement of DG and DSTATCOM for loss reduction and voltage profile improvement. Alexandria Eng. J. 57 (2018) 755-765.

[29] H. Ji, P. Li, C. Wang, G. Song, J. Zhao, H. Su and J. Wu, A strengthened SOCP-based approach for evaluating the distributed generation hosting capacity with soft open points. Energy Proc. 142 (2017) 1947-1952.

[30] H. Ji, C. Wang, P. Li, J. Zhao, G. Song, F. Ding and J. Wu, An enhanced SOCP-based method for feeder load balancing using the multi-terminal soft open point in active distribution networks. Applied Energy 208 (2017) 986-995.

[31] H. Ji, C. Wang, P. Li, J. Zhao, G. Song and J. Wu, Quantified flexibility evaluation of soft open points to improve distributed generator penetration in active distribution networks based on difference-of-convex programming. Appl. Energy 218 (2018) $338-348$.

[32] A.R. Jordehi, Optimisation of electric distribution systems: a review. Renew. Sustainable Energy Rev. 51 (2015) $1088-1100$.

[33] N. Kanwar, N. Gupta, K.R. Niazi, A. Swarnkar, R.C. Bansal, Application of TLBO for distribution network planning via coordination of distributed generation and network reconfiguration. IFAC-PaperOnLine 48 (2015) 025-030.

[34] N. Kanwar, N. Gupta, K.R. Niazi and A. Swarnkar, An integrated approach for distributed resource allocation and network reconfiguration considering load diversity among customers. Sustainable Energy Netw. Netw. 7 (2016) 37-46.

[35] M.R. Kaveh, R.-A. Hooshmand and S.M. Madani, Simultaneous optimization of re-phasing, reconfiguration and DG placement in distribution networks using BF-SD algorithm. Appl. Soft Comput. 62 (2018) 1044-1055.

[36] E. Kazemi-Robati and M.S. Sepasian, Passive harmonic filter planning considering daily load variations and distribution system reconfiguration. Electr. Power Syst. Res. 166 (2019) 125-135.

[37] E. Kianmehr, S. Nikkhah and A. Rabiee, Multi-objective stochastic model for joint optimal allocation of DG units and network reconfiguration from DG owner's and DisCo's perspectives. Renew. Energy 132 (2019) 471-485.

[38] G.I. Koong, H. Mokhlis, J.J. Jamian, H.A. Illias, W.M. Dahalan and M.M. Aman, Simultaneous network reconfiguration with distributed generation sizing and tap changer adjustment for power loss reduction using imperialist competitive algorithm. Arab. J. Sci. Eng. 43 (2018) 2779-2792.

[39] N.V. Kovački, P.M. Vidović and A.T. Sarić, Scalable algorithm for the dynamic reconfiguration of the distribution network using the Lagrange relaxation approach. Electr. Power Energy Syst. 94 (2018) 188-202.

[40] P. Kumar, I. Ali, M.S. Thomas and S. Singh, Imposing voltage security and network radiality for reconfiguration of distribution systems using efficient heuristic and meta-heuristic approach. IET Gener. Transm. Distrib. 11 (2017) $2457-2467$.

[41] Y. LakshmiReddy, T. Sathiyanarayanan and M. Sydulu, Application of firefly algorithm for radial distribution network reconfiguration using different loads. In: Third International Conference on Advances in Control and Optimization of Dynamical Systems. March 13-15. Kanpur, India (2014).

[42] L. Li and C. Xuefeng, Distribution network reconfiguration based on niche binary particle swarm optimization algorithm. Energy Proc. 17 (2012) 178-182.

[43] H. Li, W. Mao, A. Zhang and C. Li, An improved distribution network reconfiguration method based on minimum spanning tree algorithm and heuristic rules. Electr. Power Energy Syst. 82 (2016) 466-473.

[44] R. Li, W. Wang, Z. Chen, J. Jiang and W. Zhang, A review of optimal planning active distribution system: models, methods, and future researches. Energies 10 (2017) 1715. 
[45] C. Long, J. Wu, L. Thomas and N. Jenkins, Optimal operation of soft open points in medium voltage electrical distribution networks with distributed generation. Appl. Energy 184 (2016) 427-437.

[46] A. Lotfipour and H. Afrakhte, A discrete teaching-learning-based optimization algorithm to solve distribution system reconfiguration in presence of distributed generation. Electr. Power Energy Syst. 82 (2016) 264-273.

[47] C. Ma, C. Li, X. Zhang, G. Li and Y. Han, Reconfiguration of distribution networks with distributed generation using a dual hybrid particle swarm optimization algorithm. Hindawi Math. Probl. Eng. 2017 (2017) 1517435.

[48] K.N. Maya and E.A. Jasmin, A three phase power flow algorithm for distribution network incorporating the impact of distributed generation models. Proc. Technol. 21 (2015) 326-331.

[49] M. Mohammadi, M. Abasi and A. Mohammadi Rozbahani, Fuzzy-GA based algorithm for optimal placement and sizing of distribution static compensator (DSTATCOM) for loss reduction of distribution network considering reconfiguration. J. Cent. South Univ. 24 (2017) 245-258.

[50] H. Mori and H. Yokoyama, A hybrid intelligent method for estimating distribution network reconfigurations. IFACPapersOnLine 49-27 (2016) 152-157.

[51] N.F. Napis, A.F. Abd Kadir, T. Khatib, E.E. Hassan and M.F. Sulaima, An improved method for reconfiguring and optimizing electrical active distribution network using evolutionary particle swarm optimization. Appl. Sci. 8 (2018) 804.

[52] D. Nataraj, R. Loganathan, M. Veerasamy and V. Jawalkar, Optimizing radial distribution system for minimizing loss reduction and voltage deviation indices using modified grey wolf's algorithm. Int. J. Intell. Eng. Syst. 11 (2018) 177-189.

[53] T.T. Nguyen, A.V. Truong and T.A. Phung, A novel method based on adaptive cuckoo search for optimal network reconfiguration and distributed generation allocation in distribution network. Electr. Power Energy Syst. 78 (2016) 801-815.

[54] T.T. Nguyen, T.T. Nguyen, A.V. Truong, Q.T. Nguyen and T.A. Phung, Multi-objective electric distribution network reconfiguration solution using runner-root algorithm. Appl. Soft Comput. 52 (2017) 93-108.

[55] A. Onlam, D. Yodphet, R. Chatthaworn, C. Surawanitkun, A. Siritaratiwat and P. Khunkitti. Power loss minimization and voltage stability improvement in electrical distribution system via network reconfiguration and distributed generation placement using novel adaptive shuffled frogs leaping algorithm. Energies 12 (2019) 553.

[56] R. Pegado, Z. Naupari, Y. Molina and C. Castillo, Radial distribution network reconfiguration for power losses reduction based on improved selective BPSO. Electr. Power Syst. Res. 169 (2019) 206-213.

[57] L.L. Pfitscher, D.P. Bernardon, L.N. Canha, V.F. Montagner, V.J. Garcia and A.R. Abaide, Intelligent system for automatic reconfiguration of distribution network in real time. Electr. Power Syst. Res. 97 (2013) 84-92.

[58] Q. Qi and J. Wu, Increasing distributed generation penetration using network reconfiguration and soft open points. Energy Proc. 105 (2017) 2169-2174.

[59] Q. Qi, J. Wu, L. Zhang and M. Cheng, Multi-objective optimization of electrical distribution. In: Applied Energy Symposium and Forum, REM2016: Renewable Energy Integration with Mini/Microgrid; 19-21 April. Maldives (2016)

[60] A. Ram Gupta and A. Kumar, Energy savings using D-STATCOM placement in radial distribution system. Proc. Comput. Sci. 70 (2015) 558-564.

[61] R. Rajaram, K. Sathish Kumar and N. Rajasekar, Power system reconfiguration in a radial distribution network for reducing losses and to improve voltage profile using modified plant growth simulation algorithm with Distributed Generation (DG). Energy Rep. 1 (2015) 116-122.

[62] D.S. Rani, N. Subrahmanyam and M. Sydulu, Multi-objective invasive weed optimization - an application to optimal network reconfiguration in radial distribution systems. Electr. Power Energy Syst. 73 (2015) 932-942.

[63] P.D.P. Reddy, V.C.V. Reddy, T.G. Manohar, Application of flower pollination algorithm for optimal placement and sizing of distributed generation in distribution systems. J. Electr. Syst. Inf. Technol. 3 (2016) 14-22.

[64] A.V.S. Reddy, M.D. Reddy, M.S.K. Reddy, Network reconfiguration of distribution system for loss reduction using Gwo algorithm. Int. J. Electr. Computer Eng. 7 (2017) 34-39.

[65] P.D.P. Reddy, V.C.V. Reddy and T.G. Manohar, Optimal renewable resources placement in distribution networks by combined power loss index and whale optimization algorithms. J. Electr. Syst. Inf. Technol. 5 (2018) 175-191.

[66] S. Rezaeian Marjani, V. Talavat and S. Galvani, Optimal allocation of D-STATCOM and reconfiguration in radial distribution network using MOPSO algorithm in TOPSIS framework. Int. Trans. Electr. Energy Syst. 29 (2019) e2723.

[67] G.J.S. Rosseti , E.J. de Oliveira, L.W. de Oliveira, I.C. Silva and W. Peres, Optimal allocation of distributed generation with reconfiguration in electric distribution systems. Electr. Power Syst. Res. 103 (2013) 178-183.

[68] J.L. Rueda, R. Loor and I. Erlich, MVMO for optimal reconfiguration in smart distribution systems. IFAC-PaperOnLine 48 (2015) 276-281.

[69] M. Sedighizadeh, M. Esmaili and M. Esmaeili, Application of the hybrid Big Bang-Big Crunch algorithm to optimal reconfiguration and distributed generation power allocation in distribution systems. Energy 76 (2014) 920-930.

[70] R. Sirjani and A.R. Jordehi, Optimal placement and sizing of distribution static compensator (D-STATCOM) in electric distribution networks: a review. Renew. Sustainable Energy Rev. 77 (2017) 688-694.

[71] S.S.F. Souza, R. Romero and J.F. Franco, Artificial immune networks Copt-aiNet and Opt-aiNet applied to the reconfiguration problem of radial electrical distribution systems. Electr. Power Syst. Res. 119 (2015) 304-312.

[72] S.S.F. Souza, R. Romero, J. Pereira and J.T. Saraiva, Artificial immune algorithm applied to distribution system reconfiguration with variable demand. Electr. Power Energy Syst. 82 (2016) 561-568.

[73] M. Subramaniyan, S. Subramaniyan, M. Veeraswamy and V.R. Jawalkar, Optimal reconfiguration/distributed generation integration in distribution system using adaptive weighted improved discrete particle swarm optimization. COMPEL - Int. J. Comput. Math. Electr. Electron. Eng. 38 (2019) 247-262. 
[74] B. Sultana, M.W. Mustafa, U. Sultana and A.R. Bhatti, Review on reliability improvement and power loss reduction in distribution system via network reconfiguration. Renew. Sustainable Energy Rev. 66 (2016) 297-310.

[75] S.A. Taher and S.A. Afsari, Optimal location and sizing of DSTATCOM in distribution systems by immune algorithm. Electr. Power Energy Syst. 60 (2014) 34-44.

[76] Y. Takenobu, N. Yasuda, S. Minatoc and Y. Hayashi, Scalable enumeration approach for maximizing hosting capacity of distributed generation. Electr. Power Energy Syst. 105 (2019) 867.

[77] E.-G. Talbi, Metaheuristics: From Design to Implementation. A John Wiley \& Sons, Inc., Publication (2009).

[78] S. Teimourzadeh and K. Zare, Application of binary group search optimization to distribution network reconfiguration. Electr. Power Energy Syst. 62 (2014) 461-468.

[79] Y. Thangaraj and R. Kuppan, Multi-objective simultaneous placement of DG and DSTATCOM using novel lightning search algorithm. J. Appl. Res. Technol. 15 (2017) 477-491.

[80] H.B. Tolabi, M.H. Ali, S.B.M. Ayob and M. Rizwan, Novel hybrid fuzzy-Bees algorithm for optimal feeder multi-objective reconfiguration by considering multiple-distributed generation. Energy $\mathbf{7 1}$ (2014) 507-515.

[81] A.V. Truong, T.N.Ton, T.T. Nguyen and T.L. Duong, Two states for optimal position and capacity of distributed generators considering network reconfiguration for power loss minimization based on runner root algorithm. Energy 12 (2018) 106.

[82] H.K. Verma and P. Singh, Optimal reconfiguration of distribution network using modified culture algorithm. J. Inst. Eng. India Ser. B. 99 (2018) 613-622.

[83] P. Vijay Babu and S.P. Singh, Optimal placement of DG in distribution network for power loss minimization using NLP \& PLS technique. Energy Proc. 90 (2016) 441-454.

[84] C. Wang, G. Song, P. Li, H. Ji, J. Zhao and J. Wu, Optimal configuration of soft open point for active distribution network based on mixed-integer second-order cone programming. Energy Proc. 103 (2016) 70-75.

[85] C. Wang, G. Song, P. Li, H. Ji, J. Zhao and J. Wu, Optimal siting and sizing of soft open points in active electrical distribution networks. Appl. Energy 189 (2017) 301-309.

[86] T. Yuvaraj, K.R. Devabalaji and K. Ravi, Optimal placement and sizing of DSTATCOM using Harmony search algorithm. Energy Proc. 79 (2015) 759-765.

[87] T. Yuvaraj, K. Ravi and K.R. Devabalaji, DSTATCOM allocation in distribution networks considering load variations using bat algorithm. Ain Shams Eng. J. 8 (2017) 391-403.

[88] H.F. Zhai, M. Yang, B. Chen and N. Kang, Dynamic reconfiguration of three-phase unbalanced distribution networks. Electr. Power Energy Syst. 99 (2018) 1-10.

[89] L. Zhang, C. Shen, Y. Chen, S. Huang and W. Tang, Coordinated allocation of distributed generation, capacitor banks and soft open points in active distribution networks considering dispatching results. Appl. Energy 231 (2018) $1122-1131$. 